\title{
¿CONDICIONES DE VERDAD O CONDICIONES DE SATISFACCIÓN? REVISITANDO LA DISTINCIÓN AUSTINIANA DE LAS EMISIONES
}

Por:

\author{
John Alexander Giraldo Chavarriaga \\ Profesor del Departamento de Filosofía \\ Universidad del Valle \\ jagchavarriaga@gmail.com
}

\section{Resumen:}

El marco de esta reflexión es la delimitación preliminar de las emisiones realizativas, hecha por Austin en las seis primeras conferencias de How to do things with words. Considero aquí una de las distinciones de la filosofía analítica que más ha contribuido a aclarar la noción de sentido de los enunciados, la distinción entre constatativas y realizativas. Dejaré de lado la consideración de ambos tipos de emisiones como especies de actos lingüísticos en la teoría más general de los actos de habla, para centrar mi análisis en algunas condiciones que son comunes al uso de tales emisiones. La adecuación de esta distinción se logrará mostrando que la diferencia entre ambos tipos de emisiones no es de especie sino de grado y generalidad: las constatativas son un tipo especial de las realizativas, que fijan las condiciones generales de validez del discurso y se someten por igual a la doctrina de los infortunios.

Palabras claves: actos de habla, proposición, emisión, sentido, verdad, infortunio.

\begin{abstract}
:
The frame of this reflection is the preliminary delimitation of the realizative utterances, made by Austin in the six first conferences of "How to do Things with Words". Here I consider one of distinctiveness of the analytical philosophy that has most contributed to clarify the notion of the meaning of the sentences: the distinction between constatative utterances and performative utterances. I will leave aside the consideration of both types of utterances as species of linguistic acts in the more general theory of speech acts, to center my analysis in some conditions that are common to the use of such utterances. The adequation of this distinction will be attained showing that the difference between both type of utterances, is not of species but in grade and generality: the constatives are a special type of performative that state the general conditions of discourse validity and are also subject to the infelicities doctrine.
\end{abstract}

Keywords: speech acts, proposition, utterance, meaning, truth, infelicity. 


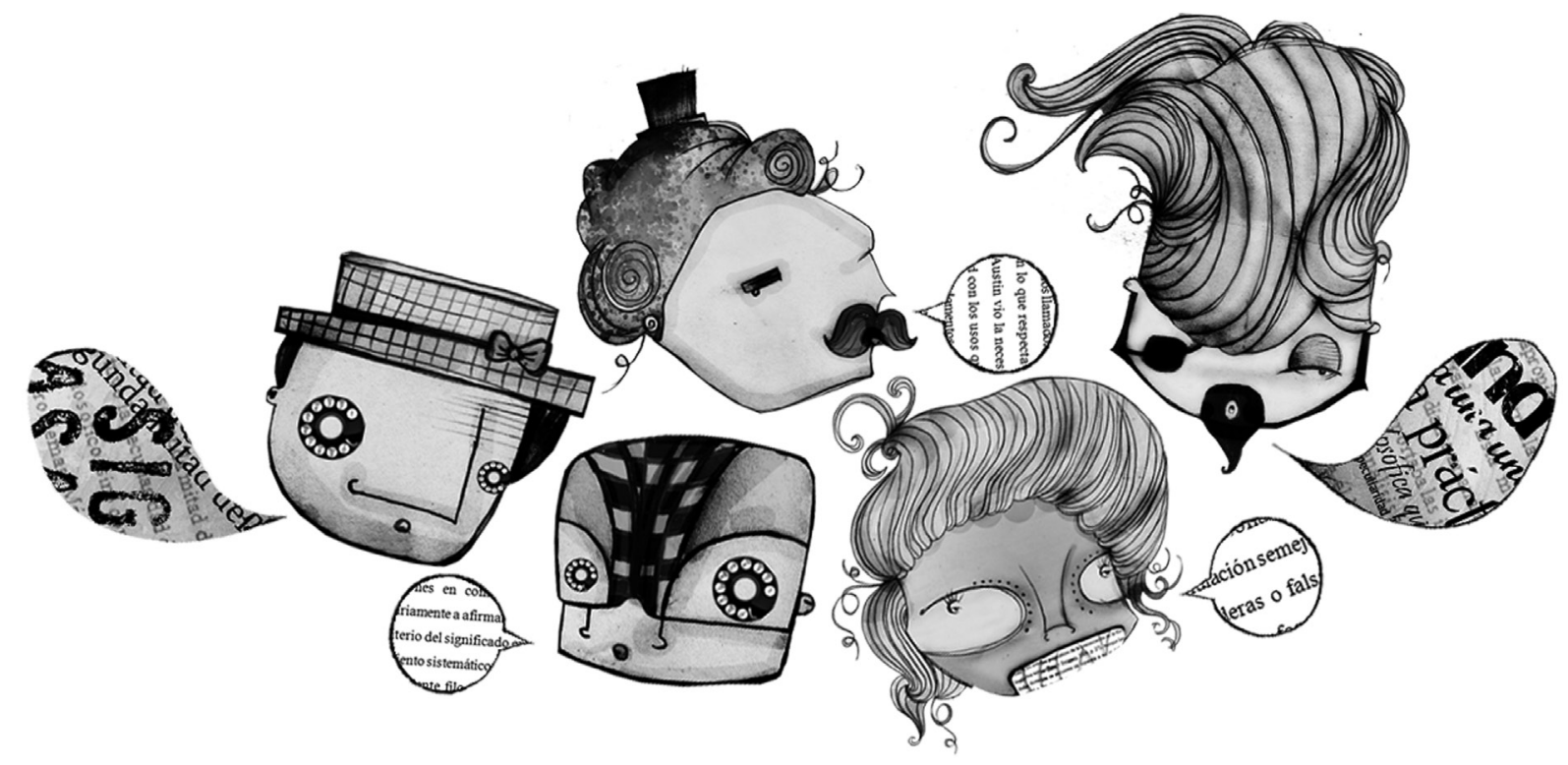

La distinción entre las emisiones constatativas y las emisiones realizativas constituye el punto de partida de los importantes trabajos del filósofo inglés John Langshaw Austin, que tanto han contribuido a los estudios pragmáticos de la comunicación en la filosofía del lenguaje y en la lingüística teórica (Pater y Swiggers, 2009:27). Aunque hay quienes consideran que dicha distinción se encuentra ya superada y no es defendible en la actualidad (Sadock, 2006: 54); sin embargo, son frecuentes los estudios que la involucran en campos como el análisis literario (Bal, 2006: 663, Mey, 2006: 549), el derecho y la política (Danet, 1980: 458, Hencher, 1980: 254, Jori, 1994, Maley, 1994, Stygall 1994), entre otros. Aún en el ámbito filosófico donde se originó, la dicotomía realizativo-constatativo sigue siendo útil, como es el caso en la actual taxonomía de los actos de habla (Searle, 1975), en la distinción entre las fuerzas ilocucionarias y los contenidos proposicionales (Searle, 1986), en los estudios de los actos de habla indirectos (Searle, 1979) o en trabajos específicos como la propuesta de Sweetser (2001) que interpreta la distinción en términos de la dirección que toma la conveniencia entre un espacio mental que es una representación y el correspondiente espacio representado.

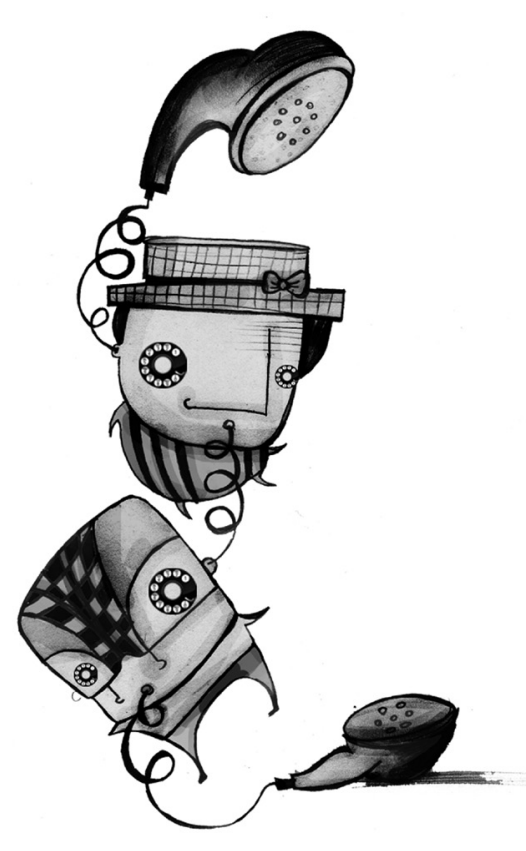

Este artículo revisita la dicotomía austiniana para mostrar cómo la caracterización temprana de ambos tipos de emisiones deja abierta espacios de interpretación que hacen posible los análisis veritativo-funcionales que son rechazados por la orientación pragmática dependiente de contexto en la que se inscribe Austin. El marco de esta reflexión crítica lo conforma la delimitación preliminar de las emisiones realizativas hecha por Austin en las seis primeras conferencias de un libro publicado póstumamente con el título How to do things with words. Dejaré de lado la consideración de ambos tipos de emisiones como especies de actos lingüísticos en la teoría más general de los actos de habla, para centrar mi análisis en algunas condiciones que son comunes al uso de ambos tipos de emisiones. Esto es consecuente con la reconsideración de que fue objeto la distinción austiniana, que en su contraste inicial es radical y, por lo tanto, inadecuada. La diferencia entre ambos tipos de emisiones no es una diferencia de especie sino una diferencia de grado y generalidad: las constatativas son un tipo especial de las realizativas, que a pesar de cumplir un propósito específico, fijan las condiciones generales de validez del discurso y se someten por igual a la doctrina de los infortunios. 


\section{El giro analítico desde el neopositivismo a la filosofía lingüística}

En la segunda mitad del siglo pasado se originó en Inglaterra una práctica filosófica que tuvo la peculiaridad de centrar su atención en el lenguaje, no sólo como objeto de estudio filosófico, sino como fuente de problemas filosóficos y, así mismo, de las soluciones a esos problemas. Más allá de constituirse como un campo o área de la filosofía, aquella práctica consistía en una metodología para afrontar problemas que requerían una aclaración conceptual. La falta de claridad conceptual era juzgada como una consecuencia del uso inapropiado del lenguaje, lo que en modo alguno sugería que el lenguaje fuera un instrumento inapropiado para la comunicación. El mal uso lingüístico era considerado el responsable de las formulaciones equívocas del pensamiento, de las que se derivan posturas filosóficas erradas. Esta metodología se propuso dar claridad a zonas oscuras del pensamiento mediante un análisis en el que el lenguaje de uso corriente, no la jerga técnica del especialista, aportaba las intuiciones necesarias para disolver la bruma que se tendía sobre las ideas. El análisis era de naturaleza lingüística y sus efectos terapéuticos obraban directamente sobre el lenguaje y sobre el amplio dominio de su influencia. La filosofía lingüística, como se le llamó, podía ocuparse no sólo de los problemas clásicos y fundamentales de la filosofía, sino de todos aquellos problemas que comprometían una falta de claridad conceptual en sus planteamientos.

El lema compartido por esta filosofía hacía del lenguaje ordinario la mejor fuente de resolución de problemas en seguimiento a las intuiciones lingüísticas del uso común (Norris, 2004: 61). El ámbito de aplicación era amplio, el espectro de dificultades asociado a las construcciones de significado desviadas del uso común requería de esta terapéutica lingüística. Los problemas de esta índole no eran tormento exclusivo de la filosofía. Prácticamente todo esfuerzo de teorización recurría a ciertas elaboraciones lingüísticas que podían ser susceptibles de cuestionarse en su base conceptual. Consecuencia de esto fue una expansión filosófica sin precedentes hacia los múltiples campos del conocimiento: "Se consideró que las técnicas lingüísticas eran aplicables, virtualmente, a cualquier campo del discurso humano" (Williams, 1993:147). Quizá esta expansión fue alimentada por una expectativa generalizada de disolver los problemas que enfrentaban diversas disciplinas tras las crisis de fundamentos que desencadenó el paradigma naturalista del positivismo. Lo cierto es que desde la segunda mitad del siglo XX hasta la actualidad, el interés por el lenguaje ha dominado todo esfuerzo teórico en busca de la claridad conceptual, fenómeno al que podría llamarse autoconciencia lingüística de las prácticas discursivas. La filosofía ligüística se practicó inicialmente en Cambridge y Oxford bajo el trabajo tutelar de Wittgenstein, Austin, Ryle, Strawson, entre otros, extendiéndose luego a Estados Unidos e influenciando a otros filósofos de Europa continental. Su impacto en las ciencias humanas y sociales ha sido apreciable, especialmente, en la lingüística, la psicología, la sociología, la antropología, los estudios culturales, el análisis literario, la comunicación social y el derecho (Reyes, 1995: 36 y 2002: 11). La apropiación de la filosofía lingüística no ha exhibido en su desarrollo la forma original de disolver los embrollos fundamentales y superar las perplejidades propias de la teorización. 
En su lugar, ha adoptando aquella metodología para orientarla al análisis de los corpus y los objetos de estudio que definen el quehacer de las diversas disciplinas que han recibido su influencia. De ello resulta que la aplicación instrumental de los marcos conceptuales y teóricos del análisis del lenguaje ordinario deja resultados que pasan a integrar el haber de conocimiento acumulado de estas disciplinas. Como ejemplo de estos marcos bastaría señalar las nociones de juegos de lenguaje y aires de familia, propuestas por Wittgenstein (1999), y la teoría de los actos de habla, desarrollada por Austin (1998) y sistematizada por Searle (1986), por no mencionar los numerosos desarrollos teóricos en torno a la presuposición, la implicatura, la intencionalidad y el contexto.

Es difícil sostener que haya unidad e identidad en el estado actual de los desarrollos teóricos que han tenido como una de sus fuentes principales a la filosofía lingüística. Sin embargo, en todo el espectro que despliega su influencia puede advertirse todavía el intento por hacer finas distinciones conceptuales que responden a diferenciaciones en el uso cotidiano del lenguaje, a menudo ilustradas con ejemplos triviales y sencillos. Este proceder analítico ha sido también fuente de crítica por la excesiva minuciosidad y el distanciamiento frecuente de una índole general de problemas. Williams (1993: 148) ilustra esta actitud desde una conocida anécdota oxoniense según la cual era frecuente que mientras Austin se encontraba en medio de un seminario haciendo finas distinciones, por ejemplo, entre hacer algo deliberadamente, intencionadamente o a propósito, era interpelado por un participante, en términos como estos: "Profesor Austin, ¿Qué grandes problemas de la filosofía iluminan estas investigaciones? A lo que Austin respondía: Aproximadamente, todos". A menos que su respuesta fuera irónica, la falta de modestia que señala esta pretensión universalista de resolución de problemas filosóficos es comparable con la del joven Wittgenstein, quien afirmó en el prólogo del Tractatus (1921) haber resuelto en lo esencial todos los problemas de la filosofía. Pese a las diferencias de estilo y pensamiento entre ambos autores ambos tuvieron en común una confianza extraordinaria en el análisis lingüístico, el uno desde las regulaciones del uso corriente, el otro desde la lógica inherente al lenguaje.

La agudeza de la mentalidad analítica al establecer distinciones conceptuales no ha sido obviamente una propiedad exclusiva de este modo de hacer filosofía, Austin solía recordar la diferenciación taxonómica de miles de especies para un cierto género en un campo de la biología denominado entomología: "Por qué no podemos descubrir nosotros exactamente ese número de distinciones acerca del lenguaje" (Williams, 1993: 152). Naturalmente, la comprensión del trabajo de Austin no debe limitarse a los alcances de sus finas distinciones, sino que debe referirse a los objetivos perseguidos y a las vías empleadas en su análisis semántico, gramatical y contextual, donde su obra supera la tradición russelliana y fregeana en filosofía (Norris, 2004: 228-9). El trabajo de Austin presenta una tensión entre los acercamientos analíticos y pragmáticos, entre la generalización de la teoría de los actos de habla y la apertura a la consideración de las numerosas y asistemáticas distinciones de los hábitos de habla corrientes en razón de la complejidad del uso del lenguaje (Norris, 2004: 232-258). El origen de la filosofía lingüística se encuentra naturalmente asociado a una distinción, aunque su mención requiere una contextualización histórica previa. 


\section{La exclusiva significatividad de los enunciados descriptivos}

Por razones históricas propias de la filosofía en su relación con el conocimiento científico, la atención filosófica al lenguaje era subsidiaria de la capacidad de éste para representar el mundo. El pensamiento acerca de los hechos del mundo en la indagación de las ciencias naturales se expresaba en su forma más simple a través de enunciados. El enunciado era considerado la expresión del hecho natural y, por extensión, del hecho social o cultural, una vez objetivados por el discurso naturalista de las ciencias sociales. El enunciado básico describía un hecho, informaba un estado de cosas de la realidad, y ese era el punto de partida lingüístico para las generalizaciones de las ciencias. La función descriptiva del lenguaje se privilegió entre sus otras funciones, bajo esta concepción positivista presente en la teoría figurativa del lenguaje del primer Wittgenstein (1921), en el atomismo lógico de Russell (1978) y en las obras de los círculos deViena y Berlín, que constituyeron el neopositivismo y el empirismo lógico (Ayer, 1978: 9-34). Los enunciados descriptivos eran considerados portadores de la verdad en correspondencia con los hechos que representaban. Esto los diferenciaba de otras emisiones lingüísticas que no eran descripciones de hechos constatables o informes acerca de un mundo objetivo.

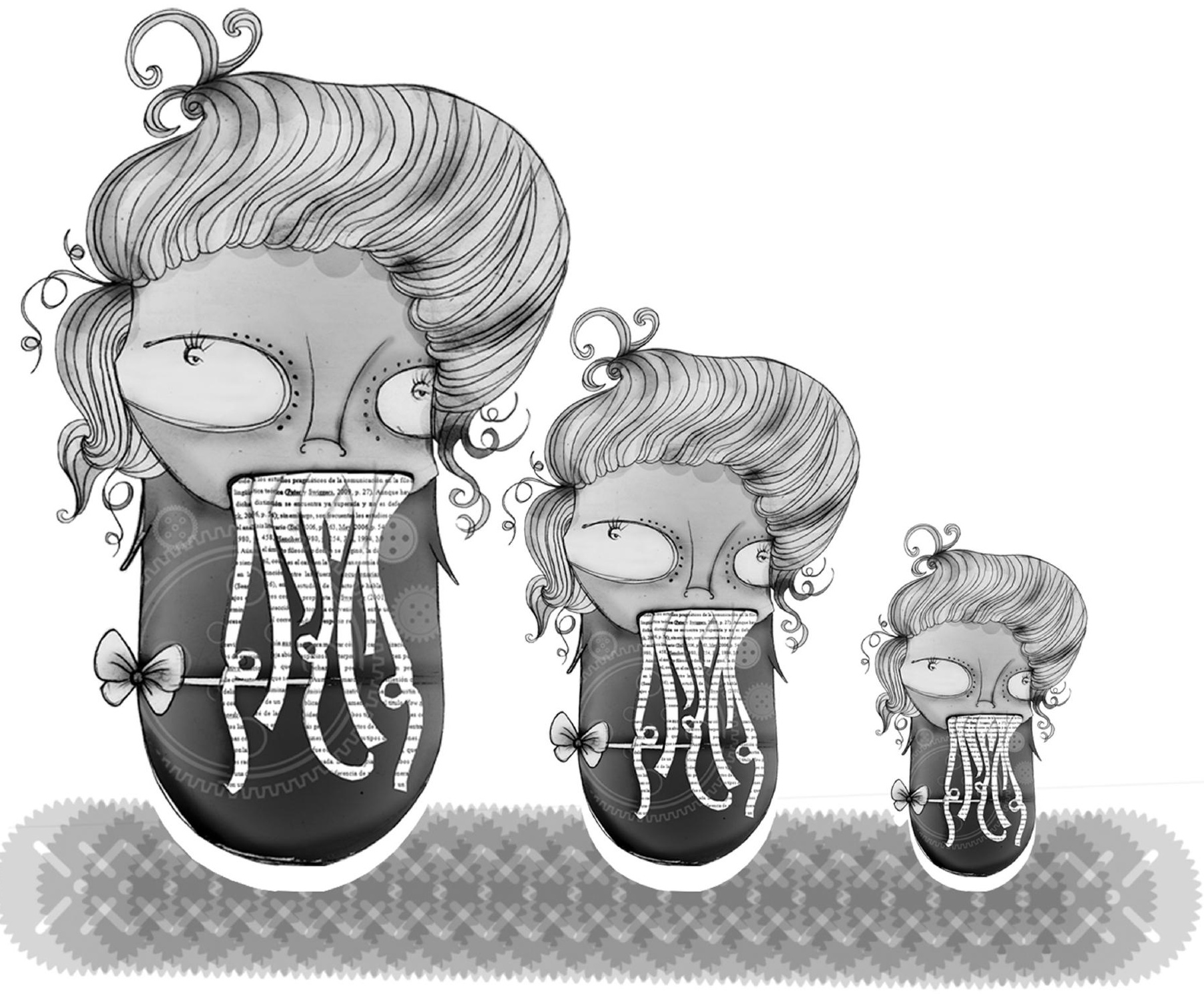


Las emisiones sin valor cognoscitivo, carentes de una representación factual con un sentido de verdad o falsedad, estaban fuera del interés de esta orientación filosófica. De este modo, se demarcó el análisis filosófico del lenguaje para una generación de filósofos que buscaba depurar el lenguaje con el fin de prestar un mejor servicio a la ciencia. El medio de depuración era la lógica, la cual garantizaba además las relaciones de deducibilidad entre los enunciados para efectos de constituir un sistema de conocimientos coherentemente articulado. Pero la lógica es un lenguaje artificial, de modo que sus proposiciones, por lo demás tautológicas, no contaban entre los tipos de enunciados reconocidos en el lenguaje natural (Carnap, 1978: 147-9). Como es sabido, toda demarcación traza un límite: algo que está adentro y algo que está afuera. En este caso, lo incluido eran los enunciados descriptivos y los excluidos la restante totalidad de las emisiones, preferencias que los positivistas identificaron genéricamente con parte de un "discurso emotivo", en el que se contaba a los juicios evaluativos propios de la estética y la ética (Searle, 1993: 197). Los excluidos en esta demarcación llevaban el signo de la falta de sentido, una presunta incapacidad para expresar lo verdadero o lo falso.

Uno de los aportes más relevantes al análisis filosófico del lenguaje bajo la nueva orientación de la filosofía lingüística fue mostrar cómo existían expresiones que a pesar de tener una formulación semejante a las expresiones asertivas, no eran susceptibles de ser llamadas verdaderas o falsas en un sentido estricto. Las razones para no calificar estas expresiones en conformidad con una semántica veritivafuncional no conllevaban necesariamente a afirmar su carencia de sentido, tal como parecía seguirse de la aplicación del criterio del significado empleado por los positivistas lógicos. Reprobando la falta de un tratamiento sistemático de los enunciados llamados 'sinsentido' y el dogmatismo habitual de la naciente filosofía analítica en lo que respecta al criterio de significación como la verificabilidad de los enunciados, Austin vio la necesidad de establecer diferencias entre algunos enunciados en conformidad con los usos que de ellos hacen los hablantes. Este planteamiento se encuentra entre los fundamentos de la pragmática (Casamiglia y Tusón, 1999: 22). Bajo esta orientación que no desdeñó la significación de las lenguas naturales reguladas por el uso y no por las prescripciones lógicas de la ciencia tuvo lugar la nueva corriente del ordinary language en el análisis filosófico (Borradori, 1996: 18-43).

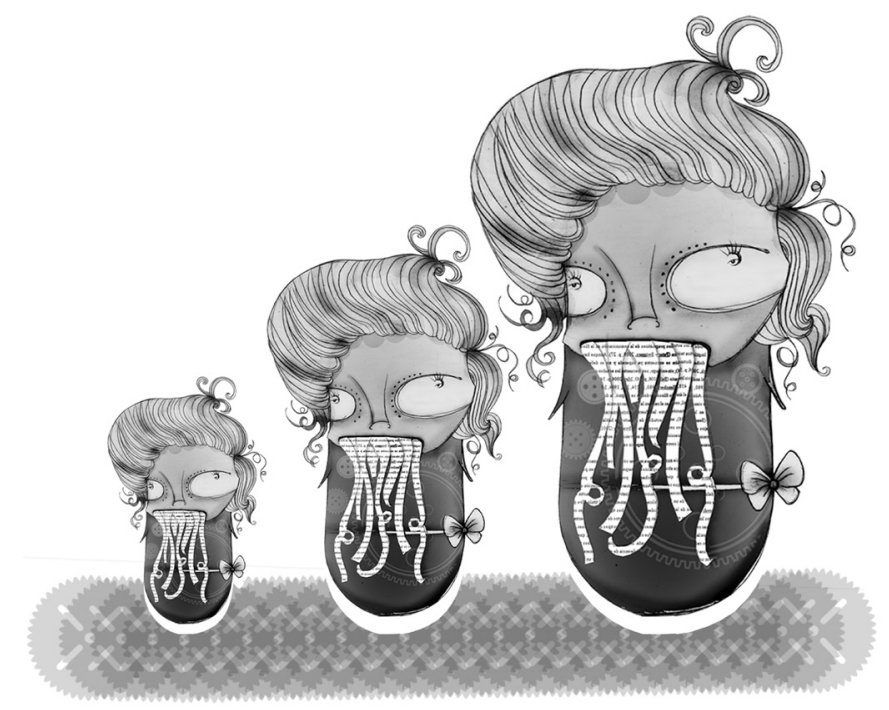


Austin advirtió en los planteamientos teóricos del positivismo en torno a la significación una falacia a la que dio el nombre "falacia descriptiva". Esta falacia, cuya denominación más acertada sería "falacia descriptivista”, consiste en la creencia de que sólo las proposiciones, es decir, las expresiones que describen eventos, sucesos, acontecimientos, hechos o estados de cosas, tienen un interés teórico para el problema de la significación (Hempel, 1978). Austin se propuso superar esta falacia en varias conferencias que fueron reunidas por J. O. Urmson y publicadas póstumamente en 1962 por Oxford University Press, bajo el título How to do things with words. Como ya se indicó, los filósofos del positivismo lógico inspirados en el Tractatus de Wittgenstein (1921) habían considerado que sólo las expresiones que pueden ser falsas o verdaderas, esto es, verificables en principio, poseían un sentido. Con este criterio, al que los mismos positivistas lógicos llamaron principio verificacionista del significado, el estudio filosófico de la significación se centró en las oraciones proposicionales, que son enunciados afirmativos, asertivos, aseverativos o descriptivos, cuyo valor de verdad está determinado por la correspondencia con los hechos a los que aluden o por la verdad o falsedad de otras proposiciones que las constituyen o de las cuales se derivan. Las restantes expresiones, que en rigor no eran susceptibles de ser llamadas verdaderas o falsas, quedaron excluidas como fuente de legítimos problemas filosóficos y su existencia fue tomada en cuenta únicamente para referirse a algún uso anómalo del lenguaje. La suerte que corrieron estos enunciados fue la de ser considerados absurdos o sin sentido (Levinson, 1983: 227) y entre ellos algunos recibieron una denominación especial: se les llamó pseudoproposiciones debido a que sus estructuras sintácticas y sus peculiaridades semánticas eran muy semejantes a las que presentaban las proposiciones. Esta corriente verificacionista del nuevo positivismo fue el pilar de la filosofía analítica vienesa, caracterizada por sus "contactos muy fuertes con la ciencia y por la formalización de su lenguaje” (Quine, 1996: 63).

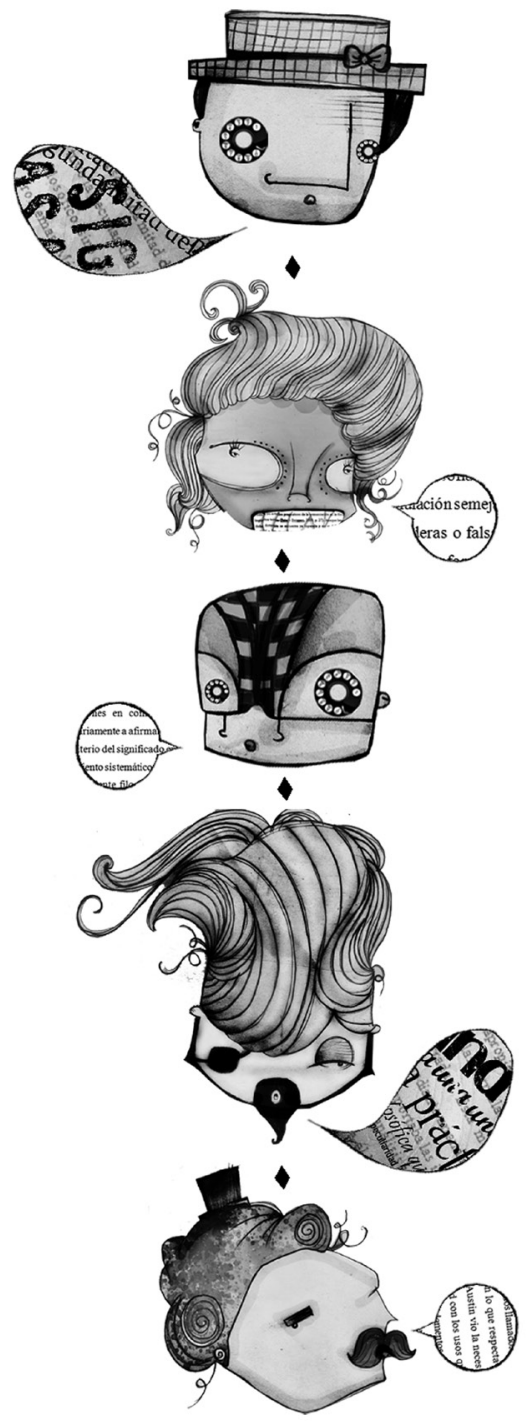

\section{Emisiones realizativas en el foco del estudio del lenguaje ordinario}

En contraste con los intereses reduccionistas de los positivistas lógicos y la hegemonía de su orientación epistemológica, la escuela analítica de Oxford y Cambridge, se orientó hacia la esfera de lo cotidiano en la que Cavell encuentra una dimensión de negatividad filosófica, ya que "poniendo la lengua en su cotidianidad, rechaza la especificidad de un vocabulario técnico” (Cavell, 1996:197). El lenguaje ordinario (every day language) exhibe muchos usos que no corresponden a los propósitos de alcanzar un conocimiento, por lo cual su función no se reduce a la declarada por la epistemología. Aun así, también en el mundo de la vida diaria, en el uso corriente del lenguaje, surgen problemas de significación que poseen su propio atractivo filosófico. Austin centró su atención en un tipo de enunciaciones de cuya significación el criterio verificacionista no podía dar cuenta. Las emisiones realizativas, como las llamó Austin, constituyeron un bloque aparte de las afirmativas o constatativas ${ }^{1}$. 


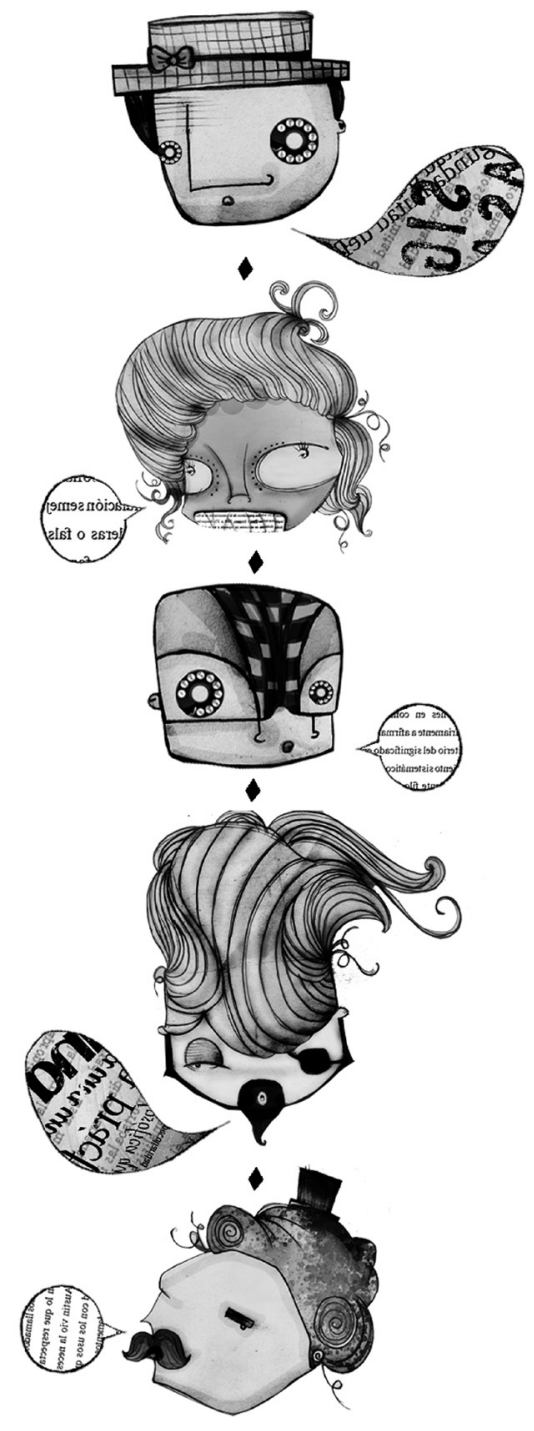

Una emisión realizativa en vez de afirmar algo o negarlo realiza el acontecimiento al que alude mediante su enunciación, es decir, hace lo que expresa (Truckenbrodt, 2004). De este modo buscó Austin el reconocimiento de una función poco advertida en el lenguaje, la función de hacer cosas y no meramente de decirlas. Esta vindicación del aspecto realizativo de ciertas emisiones en contraste con las aseveraciones fue denominada performative hipótesis (hipótesis realizativa), instaurando un punto de partida al análisis de la acción lingüística (Degand, 2006: 1009).

De cara a la postura neopositivista que intentaba superar, Austin tuvo la necesidad de justificar por qué las expresiones realizativas no hacían parte del tipo de pseudoproposiciones, de las que sí hacían parte, por ejemplo, los juicios morales o los enunciados hipotéticos o universales. Con mayor énfasis debía exponer por qué dichas expresiones no deberían ocupar el lugar marginal que la filosofía había destinado a los enunciados absurdos o sinsentido. A este respecto, es bien conocida la crítica de los positivistas lógicos a los enunciados de la ética, es decir, a los juicios morales, a los que catalogaron de pseudoproposiciones. Un destino similar corrieron los enunciados hipotéticos y las proposiciones universales a raíz de la crítica a la lógica inductivista; con la diferencia de reconocer en los primeros un necesario papel normativo en la conducta y en los segundos la pretensión del conocimiento universal de la ciencia. En la delimitación preliminar del realizativo, en la primera de sus conferencias, se expresa Austin sobre el sinsentido que está asociado a las emisiones que ocupan el centro de su atención:

El tipo de expresión lingüística que hemos de considerar aquí, no es en general un tipo de sinsentido; aunque, como veremos, el mal uso de ella puede originar variedades especiales de 'sinsentido'. Más bien pertenece a la segunda clase: a la de las expresiones lingüísticas que se disfrazan. Pero en modo alguno se disfraza necesariamente de enunciado fáctico, descriptivo o 'constatativo'. Sin embargo, es bastante común que así lo haga y, curiosamente, que ello ocurra cuando asume su forma más explícita (...). Será conveniente, en consecuencia, estudiar esta forma engañosa, para poner de manifiesto sus características contrastándolas con las de los enunciados fácticos que imitan”. (Austin, 1998: 44-45). 
Austin buscó inicialmente distinguir entre las emisiones realizativas y aquellas constatativas proponiendo una tipología que no se conformaría con los simples criterios gramaticales, si no que conduciría a la aclaración de los criterios reales de significación de las emisiones lingüísticas. Aunque Austin llamó la atención en el hecho de que las emisiones realizativas se caracterizan usualmente por la presencia de un verbo en la primera persona del singular del presente en el modo indicativo de la voz activa, no reduce a esto la distinción esencial que estas emisiones mantienen con las constatativas. La presencia del verbo realizativo en la expresión hace que esta explicite la acción, justificando su calificación como emisión realizativa explícita. Es frecuente en la lingüística centrar la atención del carácter realizativo del lenguaje en el mencionado verbo realizativo, incluso sin las especificaciones del modo y la voz, de manera que se indica que este verbo origina la acción y tiene la capacidad para ejecutar la acción que menciona (Cardona, 1991: 214). Esto resulta claro en ejemplos de emisiones realizativas explícitas como "Prometo buscarte mañana", pero también se cumple en otras emisiones usuales que cuentan como descriptivas, por ejemplo, "Te Prometo a menudo", donde es claro que no se está realizando la acción de prometer como en la anterior emisión, sino que se describe la frecuencia con que se realiza esa acción. La corrección gramatical de la segunda emisión por "Te he prometido a menudo" muestra más claramente el no cumplimiento de los criterios gramaticales específicos para la distinción, pero éste también es el caso de una emisión propiamente realizativa como: "Quedas designado a actuar en mi representación”, que no cumple con la totalidad de los criterios mencionados.

Una emisión puede cumplir con los criterios gramaticales señalados y no ser realizativa, por ejemplo: "Te busco", que describe una acción (buscar) sin realizarla. No todos los verbos son candidatos para desempeñarse como realizativos y tampoco se precisa explicitar el verbo para emitir una expresión realizativa sin que la acción realizada quede en duda. Tal es el caso en la emisión: "Desde mañana ocuparás mi lugar en la empresa", que corresponde a una designación: "Te designo en el lugar que ocupo en la empresa, a partir de mañana”. Benveniste (1966: 271-274) califica a los verbos realizativos como suireferenciales para indicar que estos verbos hacen referencia a una realidad constituida por ellos mismos, bajo condiciones de enunciación que permiten su ejecución como acción transformadora. Podría decirse con acierto que una diferencia entre los constatativos y los realizativos desde el punto de vista de la realidad extralingüística consiste en que para los primeros actúa como un referente independiente, mientras que en los realizativos dicha realidad es circunstancial, ya que el papel referencial lo tiene la realidad contextual particular creada por ellos, realidad que en modo alguno es preexistente a o independiente del acto lingüístico.

Otro criterio empleado en forma de test para distinguir entre los dos tipos de emisiones estudiadas consiste en anteponer a la formulación de la emisión la expresión: "Por la presente (oración)" (Degand, 2006: 1010-1). Considérese las siguientes emisiones: (i) "Te acuso de trasteo de votos" y (ii) "Una parte de la ciudadanía vende su voto". Al aplicar el test a (i) y (ii) se tiene: (i') "Por la presente (oración) te acuso de trasteo de votos" y (ii') "Por la presente (oración) una parte de la ciudadanía vende su voto”. 
La emisión (i') es plausible pese a ser algo protocolaria, en cambio la (ii') es anómala, pues no corresponde originariamente a una emisión realizativa. Sin embargo, basta agregar un verbo como informar o comunicar, seguido de la conjunción copulativa "que" y la expresión original (ii) satisface el criterio de uso: (ii") "Por la presente (oración) informo que una parte de la ciudadanía vende su voto". Esto muestra que en cierto modo un constatativo puede ser un realizativo, con todo lo que ello implica. Austin se vio obligado a introducir una nueva distinción entre los realizativos: realizativos explícitos y realizativos primarios, siendo estos últimos aquellos que llevan implícita la parte realizativa, mientras los primeros, aquellos que hacen uso del verbo realizativo, como puede colegirse. No obstante, al iniciar la sexta conferencia, Austin dice que:

No hay ningún criterio absoluto de este tipo (gramatical o de vocabulario) y muy probablemente, ni siquiera se puede enunciar una lista de todos los criterios posibles. Además, tales criterios no permitirán distinguir a los realizativos de los constatativos, puesto que es muy común que la misma oración sea empleada en diferentes ocasiones de ambas maneras, esto es, de manera realizativa y constatativa. Esto parece no tener remedio si hemos de dejar a las expresiones lingüisticas tal como están y nos obstinamos en buscar un criterio (1988:111).

En resumen, el análisis de Austin muestra dos cosas importantes:

1. No todo enunciado con sentido es necesariamente verdadero o falso, y

2. Existen emisiones que hacen algo además de enunciar.

Este segundo aporte de la obra austiniana no surge precisamente como una objeción a alguna de las tesis neopositivistas, sino que se presenta para poner de manifiesto la errónea y comúnmente aceptada concepción según la cual en los casos de expresiones filosóficamente relevantes, decir algo es siempre enunciar algo, y nada más que eso (Austin, 1998: 53). Considérese el siguiente ejemplo, la expresión contractual “apuesto mi reloj a que lloverá mañana”. En ella, además de la simple enunciación en boca de alguien, se está realizando la acción de apostar. Diciendo “apuesto”, apuesto. ¿Pero cuál es el papel que desempeñan las palabras dichas al apostar? Este interrogante, si se plantea en términos generales, aunque es ingenuo en apariencia, resulta fundamental para la clara delimitación del realizativo. Por una parte, si se considera que las palabras emitidas son lo único esencial al hecho de apostar, de tal suerte que apostar es sencillamente decir algo, se corre el riesgo de reducir dicha acción a las meras palabras, con lo cual estamos más cerca de una versión enunciativista (propia de la constatación) que de la real caracterización del hecho complejo que constituye una emisión realizativa, como apostar o cualquiera otra. Por otra parte, si damos poco valor a las palabras y pensamos en ellas como algo suntuario y prescindible a la acción, la distinción de los realizativos como un tipo especial de “emisiones lingüísticas” carecería de importancia y podría abandonarse.

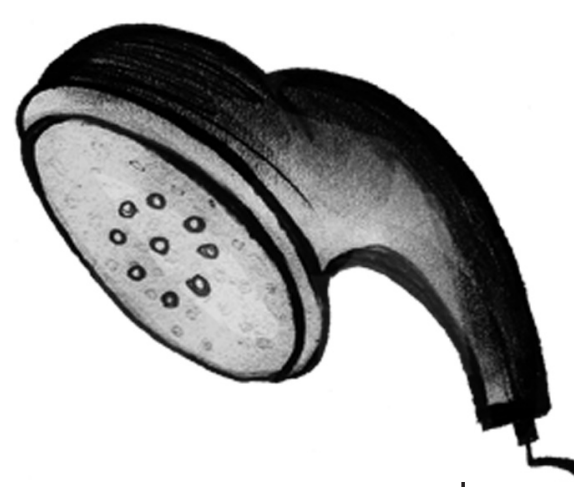


El que un apreciable número de acciones que se llevan a cabo mediante emisiones realizativas pueda realizarse felizmente sin la emisión de las palabras que ‘acompañan’ la acción, obliga a precisar la delimitación de los realizativos. Es factible que en el origen mismo de las emisiones realizativas, es decir, en las circunstancias culturales que debieron acompañar el surgimiento de expresiones lingüísticas realizadoras de acciones se encuentre un fenómeno de ritualización simbólica de una acción no lingüística. De hecho, Sorensen (2000) y Sweetser (2001) han descrito ejemplos de realizativos no lingüísticos en la magia y el ritual. Numerosos ejemplos de estos rituales y del posterior uso del lenguaje como ejercicio de un poder simbólico se encuentran descritos en la Rama dorada de Frazer (1993). El mismo Austin en su segunda conferencia dice al respecto de los infortunios, que "son una afección de la que son susceptibles todos los actos que posean carácter general de ser rituales o ceremoniales, esto es, todos los actos convencionales". La cercanía de estas ideas de Austin con el antropologismo de Wittgenstein (1976) es notable. En los realizativos explícitos de uso frecuente, la palabra tiene una connotación casi ritual: "la palabra empeñada nos obliga”, dice Austin, no sin cierto aire de solemnidad, interpelando al perjuro de sus ilustraciones. Esto permite recordar las influencias que a través de los siglos han tenido las instituciones jurídicas en la normalización del lenguaje ordinario. Con todo, una posible interpretación genética de la realización lingüística de ciertas acciones (realizatividad) como un fenómeno cultural de supervivencia ritual o de normalización jurídica del orden social no implica la adjudicación de un valor suntuario a los elementos lingüísticos que posteriormente dieron expresión a la acción. Los realizativos no son acciones a las que les sobren las palabras que los acompañan, son “emisiones lingüísticas” que realizan acciones por la vía del lenguaje:

Expresar las palabras es, sin duda, por lo común, un episodio principal, si no el episodio principal, en la realización del acto (de apostar o de lo que sea), cuya realización es también la finalidad que persigue la expresión. Pero dista de ser comúnmente, si lo es alguna vez, la única cosa necesaria para considerar que el acto se ha llevado a cabo. (Austin, 1998: 48-49).

A continuación subrayaré la relevancia que el establecimiento de un género de convención tiene como condición de posibilidad para que la expresión de ciertas palabras resulte afortunada o lleve a la cabal realización del acto que comprometen.

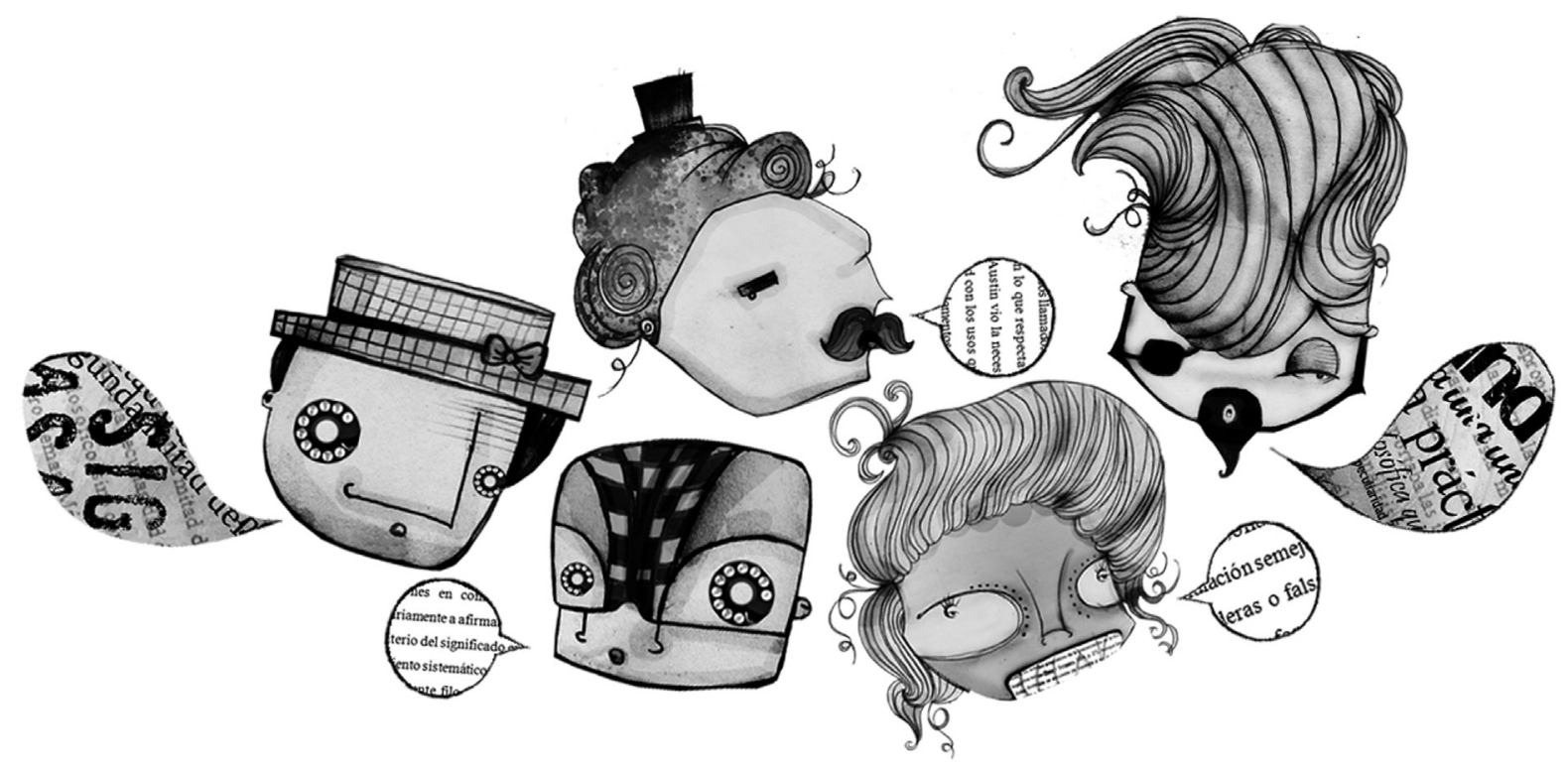




\section{La fortuna de las emisiones realizativas de espaldas a la verdad}

Como he dicho antes, las expresiones realizativas no se califican como verdaderas o falsas. De manera análoga a como una acción puede o no realizarse a cabalidad, esto es ser eficazmente ejecutada o no, las expresiones realizativas resultan fallidas, incompletas, nulas o insinceras. En términos generales, las emisiones realizativas resultan afortunadas o infortunadas de acuerdo a ciertas condiciones. Austin da el nombre de "doctrina de los infortunios" a la doctrina de las cosas que pueden salir mal o andar mal en la realización del acto aludido. Las condiciones que hacen afortunado al realizativo son, grosso modo, las siguientes (Austin, 1998: 55-56):

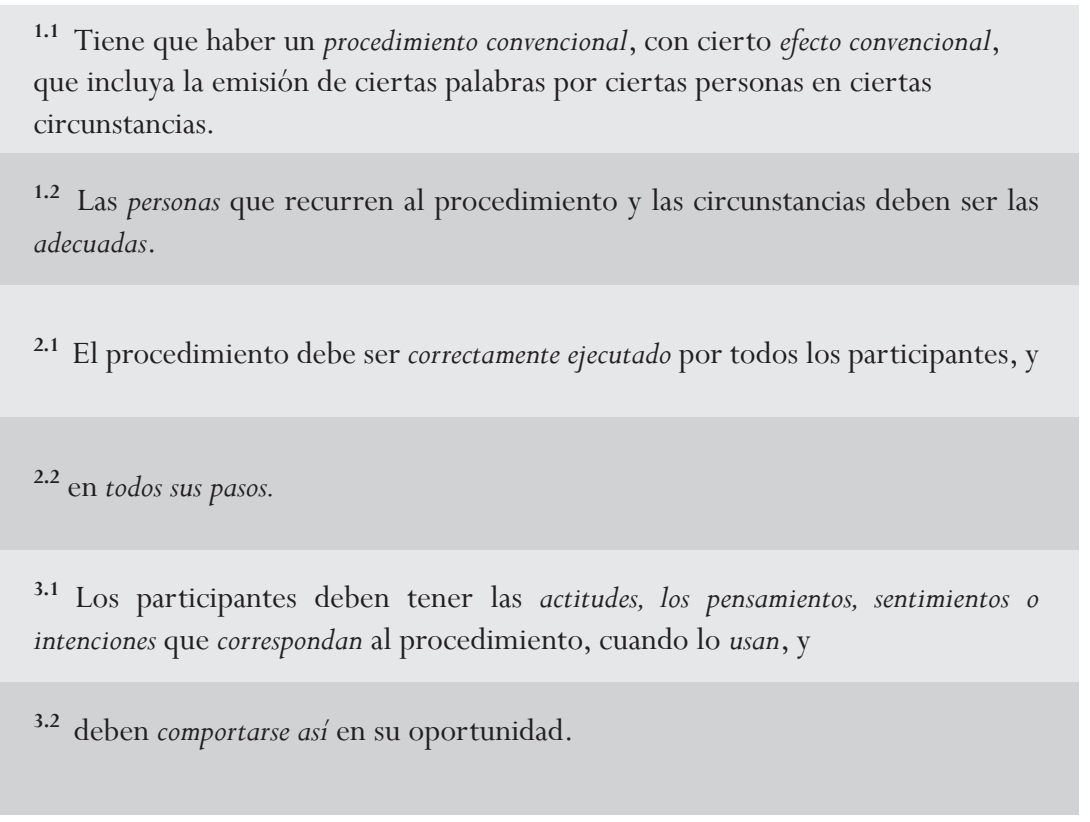

Listado 1: Condiciones que hacen afortunado al realizativo

La ausencia de alguna de estas condiciones puede ser entendida como una trasgresión de las reglas que hacen afortunada a la expresión realizativa. La violación de las reglas 1 o 2 conllevan a la práctica incorrecta del procedimiento o a la invocación de un procedimiento inútil o ineficaz. Estos infortunios reciben el nombre de desaciertos: "infortunios en los que no se consigue llevar a cabo el acto para cuya realización, o en cuya realización, sirve la fórmula verbal correspondiente” (Austin, 1998: 57). Los infortunios del tipo 3 son llamados Abusos. Ocurren cuando el acto se lleva a cabo o al menos es pretendido, pero no consumado, es decir, cuando las acciones o compromisos futuros que el acto conlleva no son o no serán realizados. Las distinciones entre los tipos y subtipos de desaciertos pueden observarse en el gráfico que se presenta a continuación, el cual reproduce, en lo esencial, el que aparece en la edición de la obra de Austin (1998: 59). Como nota aclaratoria, vale señalar que dado el carácter provisional de los nombres acuñados, y aun de la clasificación misma, Austin introduce en sus conferencias nuevos nombres (como Incumplimientos, Simulaciones, etc.) y atisba nuevos tipos de infortunios, como la "Mala comprensión", que trasgrede las dos reglas siguientes: 1. que la emisión haya sido oída por los destinatarios o interesados, y 2. que hayan entendido que la expresión realizativa era esta y no otra (Austin, 1998: 64). Al inicio de la cuarta conferencia, Austin hace especial énfasis en las fallas que producen infortunios del tipo 3.1 (Actos insinceros), a saber, 1. ausencia de los sentimientos requeridos, 2. ausencia de los pensamientos requeridos, y 3 . ausencia de las intenciones requeridas (p, 81). 


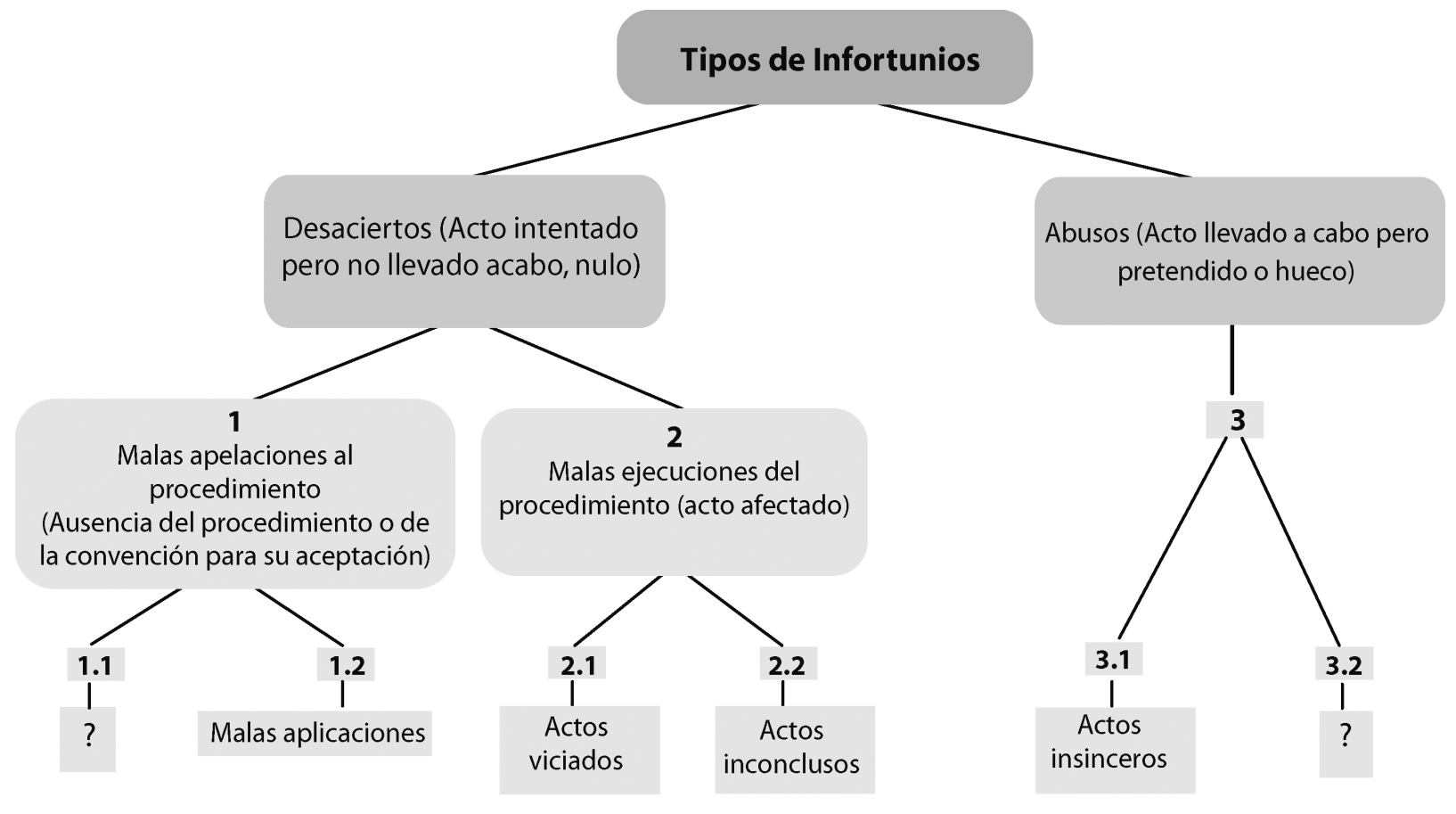

Gráfico 1: Clasificación de los infortunios

Hasta aquí he expuesto brevemente la distinción y la caracterización de los realizativos en contraste con los constatativos. Un interesante ejercicio de aplicación de esta clasificación a casos específicos de emisiones realizativas, que pueden padecer simultáneamente varios tipos de infortunios, se encuentra magistralmente expuesta al final de la segunda conferencia, a lo largo de la tercera y al inicio de la cuarta. En un ejercicio de esta índole Austin determinó con mayor precisión las condiciones de fallo de los infortunios y su identificación, sin negar, por ello, la dificultad e imprecisión de tales distinciones y su uso marcadamente provisional. En adelante, me ocuparé de la pregunta de Austin (1998: 61) sobre la pertinencia de la aplicación de la noción de infortunio a las expresiones que son enunciados, de tal modo que pueda apreciarse cómo las emisiones constatativas y las realizativas están sometidas a ciertas condiciones comunes para que su uso sea afortunado. Esta semejanza es la que permite hablar de una doctrina general de los infortunios. A continuación, buscaré establecer cuál es el parentesco (ya he tenido la oportunidad de mostrar las distinciones) existente entre ambos tipos de emisiones, de manera que quede claro el propósito específico que cumplen las constatativas con respecto a las realizativas vistas en su generalidad. Para esto me apartaré, inicialmente, de la línea de reflexión de Austin, en la que tal parentesco es visto como un error de observación que atribuye a una forma engañosa e imitativa la semejanza entre las realizativas y las constatativas. 


\section{Realización de emisiones constatativas y constatación de emisiones realizativas}

Puede pensarse que una emisión realizativa, entre otras cosas, informa un estado de cosas, como, por ejemplo, que yo pido disculpas cuando digo "disculpe usted". Sin embargo, en atención al uso verbal, se observa que en la expresión "le informo que está lloviendo", u otra cualquiera frase asertiva, es suficiente haber agregado un verbo como informar, afirmar o aseverar, para hacer explícito el uso informativo de la expresión, mientras que en el tipo de expresiones realizativas, además de esto debe agregarse otro verbo para que el sentido de lo que se dice sea explícito. Así, puede decirse "le informo que le he pedido disculpas", pero es anómalo decir "le informo que me disculpe". En el primer caso, el verbo informar aparece con un uso aclaratorio o reiterativo al hecho de pedir disculpas y, por lo tanto, altera la frase original de tal manera que las expresiones: "le reitero mis disculpas" o "aclaro que le he pedido disculpas" bien podrían reemplazarla, según sea el caso. Decir, en cambio, "llueve" o "informo que está lloviendo" son perfectamente intercambiables, de tal suerte que el verbo 'informar' poco o nada agrega al sentido original de la expresión: en ambas frases se alude al evento de llover, afirmándolo.

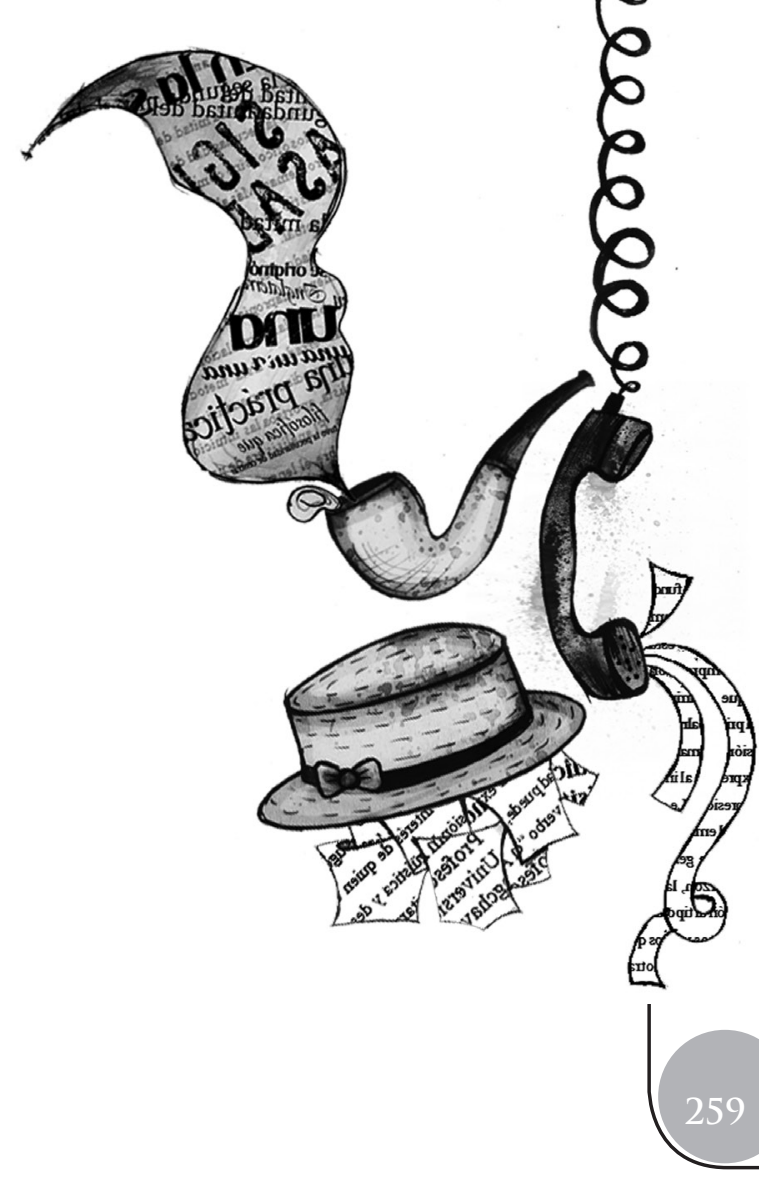

Aunque no es pertinente adjudicar un uso esencialmente informativo a las emisiones realizativas, queda claro que el uso de expresiones informativas derivadas de las realizativas a menudo contribuye a la fortuna de éstas últimas. De igual manera, a pesar de su menor "fuerza", estas expresiones informativas "hacen las veces" de realizativas para ciertos oyentes (entre ellos podría contarse a los obstinados, los meticulosos y los distraídos) o en ciertos contextos (por ejemplo, en aquellos donde la prudencia aconseja el uso de una expresión de menor fuerza). Me refiero aquí a la fuerza ilocucionaria, término que acuña Austin en la denominada "segunda teoría" o "teoría general de los actos de habla". Dadas las limitaciones temáticas de este artículo no me ocuparé de dicha noción. En efecto, Austin (1975: 228-229) no fue del todo ajeno a este acercamiento en los usos de las emisiones constatativas y de las realizativas, e incluso llegó a considerar que se había fiado demasiado del contraste que ofrecía la distinción tradicional entre ambos tipos de emisiones. Por esta razón, dejó abierta la posibilidad de establecer un paralelo entre las constatativas y las realizativas en el análisis de los males que padecen estas emisiones. La sugerencia de Austin apunta a la generalización de la doctrina de los infortunios en una teoría de los actos de habla donde el análisis binario de la dicotomía constatativo/realizativo se desarrolla hasta ser sustituido por el análisis tripartito del acto de habla que realiza toda emisión, en tres términos: locionario, ilocucionario, perlocucionario (Norris, 2004, p. 228). Esta sustitución de la distinción preliminar suele ser vista como una ruptura en el pensamiento de Austin a favor de la sistematicidad de sus estudios (Proudfoot y Lacey, 2010: 386-7 y Levinson, 1983: 231). 


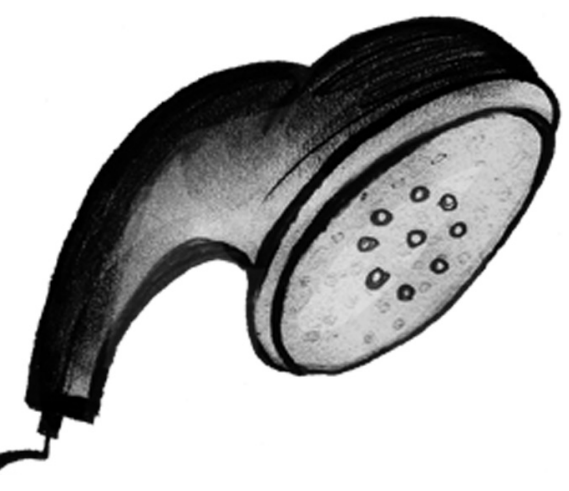

Antes de exponer las razones para esta generalización en términos de las condiciones de verdad de los enunciados, conviene hacer un par de precisiones sobre aquellos fenómenos que podrían llevar al uso de expresiones informativas para contenidos realizativos, como en los ejemplos anteriores, o al uso de verbos que hagan explícita la fuerza del realizativo, como se verá a continuación. El análisis precedente del uso de un verbo como 'informar' u otro semejante al ser introducido en una expresión realizativa típica no debe extenderse a otros tipos de verbos, cuya función sea la de aclarar las intenciones del hablante al emitir un realizativo. Tómese como ejemplo la expresión “¡Vaya!”. Aquí el verbo en imperativo sugiere que quien la emite está dando una orden, pero puede suceder que haya cierta ambigüedad en la comprensión y dicha emisión sea tomada por una sugerencia o una exhortación, lo que ocurrirá con mayor frecuencia si el interés de quien escucha (el interlocutor) está principalmente dirigido a la mera expresión lingüística y desatiende la fuerza de la emisión misma. Dicha ambigüedad puede, no obstante, evitarse aclarando el "sentido" de la expresión al introducir en ella el verbo "ordenar", distintivo de ese tipo de realizativo. La expresión "Le ordeno que vaya" no deja dudas de los efectos que quiere producir su locutor al emitirla, que pueden coincidir con los efectos perlocucionarios, es decir, con aquellos que genera o produce efectivamente lo dicho en el interlocutor o auditorio. Por esta razón, la expresión anterior se clasifica en el tipo de realizativos explícitos en oposición al tipo de realizativos primarios o implícitos como “ ¡vaya!". En definitiva, el uso de estos verbos que hacen explícito el realizativo no introduce cambios sustanciales, en tanto que una y otra emisión (explícita e implícita) hacen prácticamente lo mismo (ordenar) (Austin, 1998:74). No ocurre igual al introducir verbos como informar $\mathrm{u}$ otros apropiados a las emisiones constatativas, pues, como ya vimos, éstos introducen una novedad en el sentido de la expresión y hacen, en efecto, una cosa diferente: cumplen un propósito que deja de ser el propósito originario.

Sumariamente, Thomas (1995: 44-46) ha indicado las razones por las que falla la hipótesis realizativa de Austin: I. No hay manera de distinguir gramaticalmente los verbos realizativos de los que no lo son, II. la presencia del verbo realizativo no garantiza la identidad realizativa de una emisión y III. muchas emisiones habituales que podrían ser realizativas sin duda no involucran verbos realizativos e incluso para algunas de ellas no existe en la lengua el verbo realizativo correspondiente a la acción. Al emitir una proposición es cierto que estamos haciendo algo: afirmamos o negamos algo, que en el caso de las proposiciones descriptivas llamamos un hecho. En la mayoría de los casos, ese hecho pertenece a una realidad extralingüística, salvo cuando el objeto de la proposición es lo que alguien ha dicho o pensado, como ocurre en las expresiones que tienen verbos de actitudes proposicionales (por ejemplo: creo, pienso o dudo). 
Este aspecto en común entre los constatativos y realizativos, a saber, que ambos son "haceres", viene matizado por la diversidad del hacer de las emisiones realizativas, que es, dicho sea de paso, más extenso y cobija todos los verbos conjugados en primera persona del singular del presente del indicativo en la voz activa, según el polémico criterio ya discutido. Pero, ¿hay que descartar que los constatativos, como actos informativos, están expuestos a las deficiencias a que están expuestos los realizativos en términos de la ejecución de los actos que les corresponden? Si en efecto se hallan igualmente expuestos los constatativos y los realizativos, surge un importante interrogante: ¿es extensible la doctrina de los infortunios al análisis del uso de las emisiones constatativas?

Para abordar esta pregunta, como es costumbre en la tradición analítica en filosofía, Austin parte de los casos anómalos o chocantes que se presentan en el uso de ciertas aserciones. Para determinar dónde reside la falla de algunos tipos de enunciados constatativos, Austin retoma algunos ejemplos polémicos y de larga trayectoria en el debate filosófico en torno a la significación. El análisis de la oración: "El actual Rey de Francia es calvo", es uno de ellos y con él pone de manifiesto la dificultad de presuponer la existencia de un referente para ciertos tipos de enunciados. La sugerencia que Austin (1998: 81-95) hace al respecto tiene que ver con la impertinencia de llamar a estos enunciados falsos o verdaderos más bien que nulos (u otra asignación similar). Si Francia no es actualmente una monarquía, quien profiere la emisión en cuestión habrá empleado una formula verbal para predicar un atributo de un sujeto sin lograr afirmar esa atribución por la falta de referencia de la expresión definida (sujeto gramatical). El acto de afirmar no se realiza, se intenta pero sin llevarse a cabo por un vicio en el procedimiento (ha fallado la presuposición de existencia). De acuerdo con este análisis, los constatativos pueden resultar infortunados en un sentido análogo al fracaso que experimentan los realizativos. Los enunciados (constatativos) pueden resultar contradictorios o insinceros o pueden errar con falsos presupuestos (Sadock, 2006: 57). Austin, en efecto, advirtió esta semejanza como algo más que un paralelo, como una condición común que se revelaría en una teoría general de la acción lingüística.

Vemos que para explicar qué es lo que puede andar mal con los enunciados no podemos limitar nuestra atención a la proposición en juego (sea lo que esto fuere), tal como se ha hecho tradicionalmente. Tenemos que considerar la situación total en que la expresión es emitida -el acto lingüístico total- para poder ver el paralelo que hay entre los enunciados y las expresiones realizativas, cómo unos y otros pueden andar mal. Quizá en verdad, no hay una gran diferencia entre los enunciados y las expresiones realizativas (Austin, 1998: 95). 
Lo esencial de la respuesta a la pregunta por la ampliación de la doctrina de los infortunios al análisis del uso de las emisiones constatativas, queda planteado cuando Austin pone de manifiesto que para una emisión ser afortunada tiene que satisfacer ciertas condiciones, y, por tanto, los enunciados que "presentan" (o que garantizan directamente mediante un informe de las circunstancias) dichas condiciones tienen que ser verdaderos. ¿Cuál es la relación, por ejemplo, entre el realizativo "le pido disculpas" y el hecho de pedir disculpas? Hay que llamar la atención en que esta relación no puede ser del tipo existente entre una aserción (o constatativa) y el hecho correspondiente, ya que, en palabras de Austin, "es la fortuna del realizativo 'le pido disculpas' lo que constituye el hecho de que estoy pidiendo disculpas, y mi realización satisfactoria del acto de pedir disculpas depende de la fortuna de la expresión realizativa 'le pido disculpas'” (Austin, 1998: 90). Esta fuerte e indisoluble dependencia (bidireccional) entre el acto y el decir, que constituye al realizativo, contrasta con la relación de correspondencia entre el mero decir y el "aislado" hecho referido en las expresiones constatativas.

No obstante, entre la acción y la expresión se tiende un contexto de significatividad que tiene elementos extralingüísticos que repercuten en las aserciones que pueden hacerse en torno a la expresión realizativa para dar cuenta de su feliz realización. La complejidad de este contexto es una de las razones que han tenido los filósofos de la escuela del lenguaje ordinario, entre ellos Austin, para considerar ilegítimo el tratamiento lógico formal de los efectos extralingüísticos de contexto en las condiciones de verdad de las aserciones (Stanley, 2007: 31). Sin embargo, el punto más polémico puede estar en suscribir a la fortuna de las emisiones realizativas ciertas condiciones de verdad bajo la consideración de las correspondientes aserciones como partes constitutivas de la emisión realizativa.

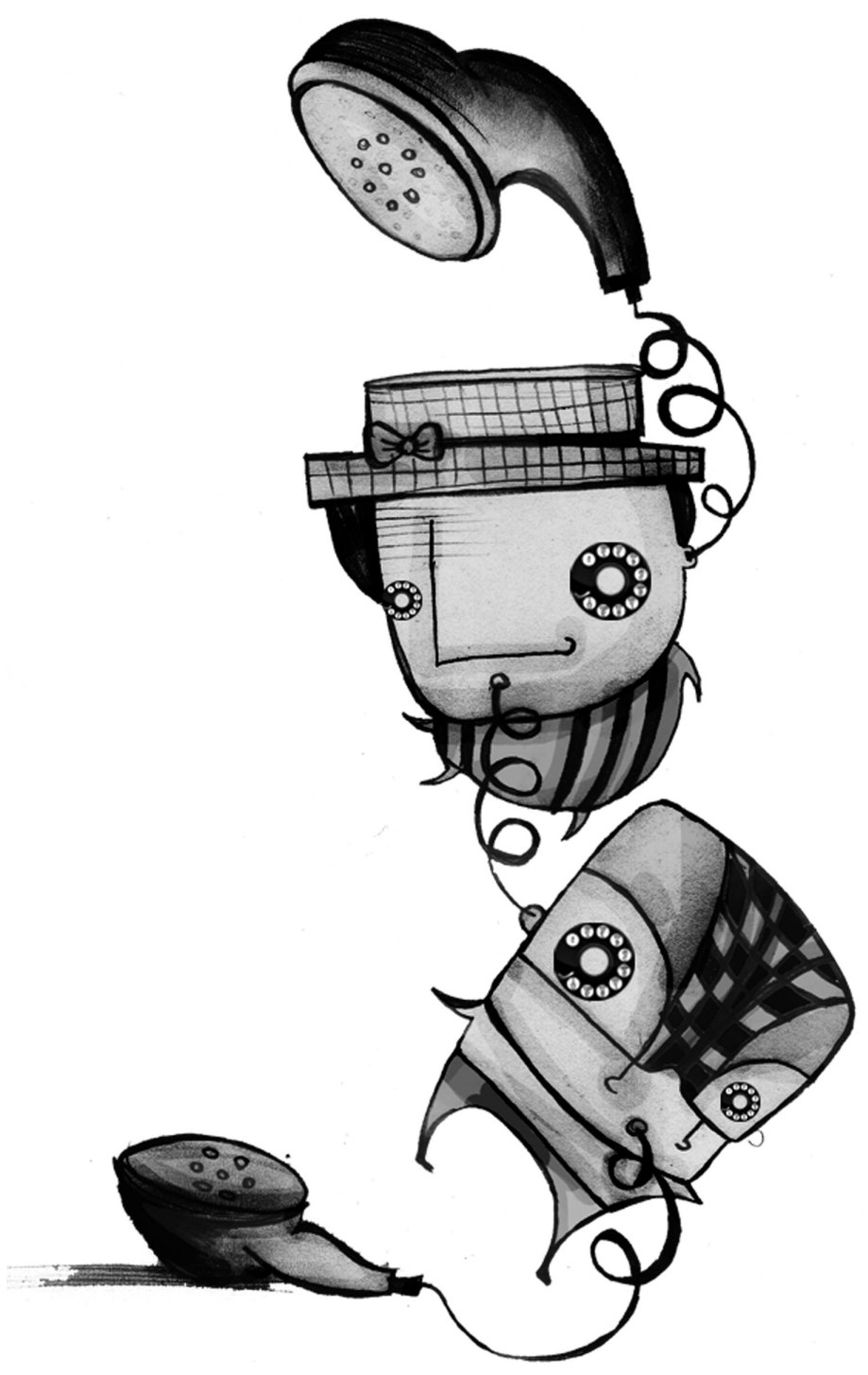




\section{Realizatividad y compromiso con la verdad: ¿hay o no condiciones de verdad?}

En lo siguiente me concentraré en mostrar ciertos compromisos que las emisiones realizativas adquieren con la verdad de algunas emisiones constatativas que se encuentran asociadas a ellas por la vía de las condiciones de su realización satisfactoria. Este intento podrá valer como un acercamiento al análisis formal de las emisiones realizativas sólo en la medida en que aclaran parte de su estructura semántica ante efectos extralingǘsticos restringidos no ligados a contextos específicos. Obviamente, el estudio formal de las condiciones de verdad de las emisiones hace parte de la tradición semántica frente a la cual la pragmática postuló la adscripción de verdad o falsedad en las condiciones de uso de la expresión.

Pero la temprana oposición entre semántica y pragmática se considera hoy superada, reconociéndose la complementaridad de sus aportes (Recanati, 2006: 443). Un punto de encuentro radical entre ambas tradiciones lo constituyen los acercamientos a los aspectos comunes de la distinción, en términos de la adscripción de valores de verdad. El trabajo de Bach (1975) fue uno de esos intentos tempranos por mostrar que es un error considerar que las emisiones realizativas no sean constatativas es decir susceptibles de verdad o falsedad. El punto de partida de Bach es el uso ordinario de expresiones realizativas primarias usadas para hacer afirmaciones verdaderas o falsas (Bach, 1975: 229). En un trabajo posterior, Bach y Harnish mostraron que una "oración realizativa cuando es usada literalmente hace una afirmación, de manera directa, y realiza la acción correspondiente al tipo de acto de habla referido por el verbo, de manera indirecta" (1992: 98). No obstante, se trata de una tesis polémica como ha quedado evidenciado con los argumentos de Reimer (1995) en su rechazo.

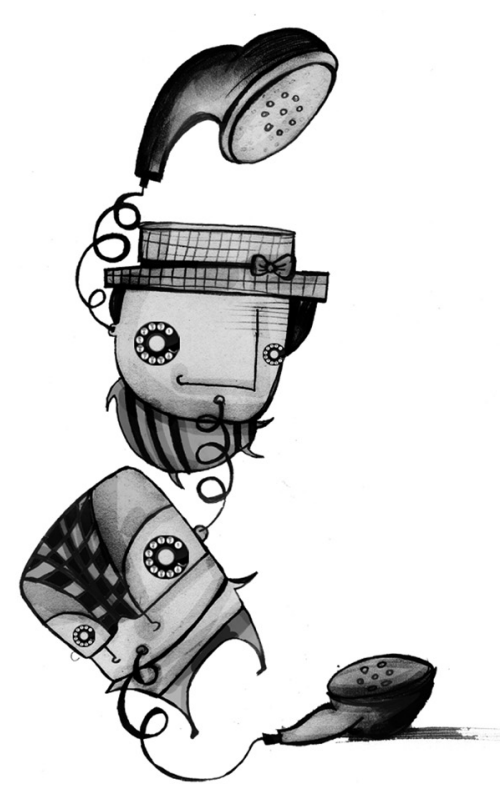

En lo que sigue intentaré hacer explícitas las verdades básicas que se derivan de la realización afortunada de una emisión realizativa, en términos del cumplimiento de sus condiciones de realización. Mediante esta estrategia busco asociar a una emisión realizativa una serie de enunciados (constatativos) que comprenden tanto aquel que constata la acción realizada por la emisión realizativa, como aquellos que constatan el cumplimiento de todas y cada una de las condiciones de garantizan la realización afortunada de la emisión realizativa según la doctrina de los infortunios antes expuesta.

1. Es verdad, y no falso, que estoy haciendo (de hecho) algo; en realidad estoy haciendo numerosas cosas, pero en particular, por ejemplo, estoy pidiendo disculpas (en un informe posterior diría: "he pedido disculpas");

2. Es verdad, y no falso, que se dan ciertas condiciones, en particular las del tipo especificado en las reglas 1.1 y 1.2 ;

3. Es verdad, y no falso, que se dan otras condiciones de nuestro tipo 3., en particular que estoy pensando algo; y

4. Es verdad, y no falso, que estoy comprometido a hacer algo subsiguientemente.

Listado 2: Relaciones de verdad entre constatativos y realizativos 
Las relaciones entre los constatativos y los realizativos en términos de la verdad de los primeros y la fortuna de los segundos pueden ser apreciadas esquemáticamente del siguiente modo:

Formalizaré ahora estas condiciones de for tuna de los realizativos, que han sido expresadas mediante enunciados (constatativos) como condiciones de verdad. Con ello espero poder observar más claramente el sentido (dirección) y las relaciones semánticas presentes entre ambos tipos de emisiones:

Sea:

$\mathrm{R}$, una expresión realizativa cualquiera;

C, el enunciado constatativo de R;

$\mathrm{P}_{\mathrm{ij}}$ una expresión constatativa que enuncia la condición $\mathrm{I} . \mathrm{j}$,

Donde i varia entre 1 y 3 , y j es 1 o 2 (ver listado 1$){ }^{2}$

A y I las asignaciones de valor afortunado o infortunado, respectivamente; $y$

F y V las asignaciones de verdad;

Para abreviar, basta anotar R para simbolizar R es A, y $\mathrm{P}$ para simbolizar $\mathrm{P}$ es V; para los casos en que $\mathrm{R}$ es I o $\mathrm{P}$ es $\mathrm{F}$ debería anotarse la expresión antecedida del operador lógico de negación $(\neg)$, ya que este operador invierte el valor de la asignación, así: $\neg \mathrm{R}$ o $\neg \mathrm{P}$.

Tenemos que:

1. $\mathrm{R} \rightarrow \mathrm{C}$

2. $\mathrm{R} \rightarrow\left(\mathrm{P}_{11} \wedge \mathrm{P}_{12}\right)$

3. $\mathrm{R} \rightarrow \mathrm{P}_{31}$

4. $\mathrm{R}^{\mathrm{c}} \rightarrow \mathrm{P}_{12}$

Examinaré ahora este resultado que exhibe ciertas relaciones de inferencia, con algunas ideas que Austin (1998: 90-95) introduce al final de la cuarta conferencia, al indicar que la noción de verdad puede ser implicada en unas expresiones por la vía de otras expresiones. Con esto espero que las inferencias a las que se alude puedan ganar en riqueza semántica. Los modos como la verdad de un enunciado está siempre acompañada de la verdad de otro enunciado se hacen patentes al advertir cierta 'incompatibilidad' entre dos o más enunciados fácticos. Esto quiere decir, que siempre que afirmemos un enunciado a la vez que neguemos, en cualquiera de sus formas, otro enunciado (que deberíamos afirmar) cuya verdad se relaciona estrechamente y directamente con la verdad del primero, incurrimos en un error o en una manera abusiva de hablar. 
Puesto que Austin advertía que la noción de contradicción era insuficiente y que su particularidad no permitía extenderla a los casos que aquí son de interés, recurro aquí al término 'incompatibilidad', también usado en la lógica formal, aunque en un sentido algo diferente. A pesar de que Austin, examinando la segunda de las maneras como la verdad es implicada, llegó a rechazar el término "incompatibilidad", acudo a él por lo que representa conceptualmente, a falta de otro mejor y más general, y no por su valor operacional específico (como juntor binario conocido como una de las barras de Sheffer). De este modo, no debe entenderse que con esta acepción aludo únicamente a proposiciones no analizadas y consideradas en un sentido formal restringido. Hecha esta aclaración, la implicación de verdad suele presentarse en tres formas (Gómez, 1988: 59-82):

1. Implica lógicamente (exigencia lógica que está presente en las inferencias bajo el rótulo "se sigue de" $[\rightarrow]$ ).

2. Implica (en el sentido de George Edward Moore, el cual corresponde a cierta coherencia entre lo afirmado y la creencia de que ello es así; esta es una exigencia un tanto pragmática).

3. Presupone (presuposición de existencia en el sentido aclarado por Peter Strawson).

Creo que es correcto afirmar que cada una de estas tres formas de 'implicación' de la verdad tiene, en la esfera lógica, un dominio ejemplar asociado. Así, el dominio del primer caso, es el de todas las inferencias posibles y lícitas del famoso cuadro lógico (que vincula enunciados universales y particulares, tanto negativos como afirmativos, entre sí por medio de relaciones de contradictoriedad, contrariedad, alternidad y subalternidad, entre otras). En el segundo caso, se encuentran todos los enunciados asertivos respecto de los cuales otros enunciados que se refieren a ellos, empleando verbos de actitudes proposicionales como creer, deben ser verdaderos necesariamente. El tercero abarca aquellos casos de inferencia, o de simples aserciones, donde la verdad depende de una o más premisas que deben especificarse y que refieren, al menos la mayoría de las veces, a la existencia de sujetos lógicos.

Las relaciones inferenciales entre los enunciados pueden ser de un gama más amplia que la señalada anteriormente. Esta ampliación no sólo se presenta desde un punto de vista lógico sino también desde un punto de vista semántico en el que la concepción misma de la verdad puede cambiar, modificando así las inferencias que se pueden considerar válidas. Bajo una concepción débil de verdad como aquella que se presenta en la atribución de verdad en los juicios cotidianos tendríamos otras relaciones inferenciales. Por ejemplo, cuando alguien especifica el color de su mascota, digamos, un perro de raza schnauzer, puede decir ciertamente que es gris, de lo cual no debe inferirse que sea falso que sus patas son de color blanco. Este sentido de verdadero como "parcialmente verdadero" o "aproximadamente verdadero" no sigue la rigurosidad esperada de una concepción adaptada a las necesidades lógicas de deducibilidad. Afecta, por tanto, el conjunto de aserciones que se considera válido respecto de un enunciado, relativizando el valor de verdad (Dummett, 1994: 44). 
Esta fue una de las razones por las cuales Austin encontró que no todos los constatativos eran asequibles en términos de condiciones veritativas en un sentido estricto (Huang, 2006: 1002). Los ejemplos que ilustraron esa limitación fueron: "France is hexagonal", "The fridge is empty" y "New York is sixty miles from where I live". Los grados de precisión en las descripciones sobre el mundo o la riqueza de la información suministrada responden a los intereses y propósitos de la actividad de la que hacen parte.

Esto resulta compatible con la idea natural e intuitiva según la cual una oración porta un valor de verdad sólo si tiene un potencial informativo, esto es, si expresa un contenido proposicional (Alston, 1997: 13). La verdad del enunciado en un sentido relativo a su contenido informacional y las inferencias que puedan ser o no admitidas a partir de ese contenido están en función de la relevancia que adquieren en el contexto de emisión del enunciado para los interlocutores. De este modo, la aceptación de la verdad de un enunciado en marcos de enunciación como el discutido, no responde únicamente a una relación de dependencia con otro enunciado del que pueda derivarse.

La no dependencia conceptual sino contextual da lugar a un análisis semántico diferente al que se propone el presente artículo, razón por la cual no se ha considerado.

Para finalizar me permitiré una última cuestión: ¿qué ocurre cuando alguien emite determinada expresión y se encuentra que su verdad no es compatible con otra que bien puede ser proferida por otra persona o que podría formular un tercero refiriéndola a ciertas actitudes de la persona en cuestión? Pues bien, la respuesta en términos generales es que estamos frente a un tipo de infortunio, ya sea de aquellos que implican la creencia en lo dicho y se trate de un caso de insinceridad (como afirmar algo sin creerlo), o bien de nulidad (cuando el procedimiento de afirmar se neutraliza porque la expresión que quiere afirmarse no es objeto de afirmación, es decir, no es verdadera ni falsa, y, sin embargo, posee significado), o, incluso, de auto-anulación de un compromiso (cuando una afirmación o una realización no se siguen de otra afirmación u otra realización que están comprometidas por las primeras).
Así, el compromiso de verdad que deben arrastrar ciertas emisiones constatativas no sólo puede encontrar una formulación general aunque sin duda incompleta, en términos de los infortunios correspondiente a los tres tipos de condiciones propuestos por Austin en su doctrina, también podría aplicarse a las emisiones realizativas de tal forma que su fortuna se evalué en términos de condiciones de verdad expresadas por los enunciados que asociados a ellas según se ha visto.

Esto muestra, aunque no con la prolijidad que debiera, la pertinencia de los interrogantes hasta aquí planteados, y da un bosquejo de las respuestas sugeridas a dichos interrogantes.

En conclusión, esta reflexión crítica sobre la distinción entre emisiones constatativas y emisiones realizativas ha intentado mostrar: I. La relevancia filosófica que el reconocimiento y la comprensión de los realizativos tuvo para el abandono de viejas y erradas opiniones filosóficas en torno a la caracterización de las expresiones filosóficamente importantes, II. La superación de la restringida y reduccionista tesis verificacionista del significado por la vía del reconocimiento del significado ligado a la acción en emisiones usuales del lenguaje corriente; III. El carácter provisional de los criterios de distinción de las emisiones realizativas, de acuerdo con sus peculiaridades propias y con sus diferencias frente a los constatativos; IV. Los usos específicos de ambos tipos de expresiones puestos en relación con ciertas acciones que pueden sugerir los verbos empleados en sus enunciaciones; V. La necesidad de una doctrina de los infortunios completa que explique los yerros de las emisiones constativas y procure su clasificación; VI, los compromisos veritativos de los realizativos para su realización afortunada, evaluados en enunciados (constatativos) que expresan la realización de la acción correspondiente y las condiciones de fortuna, VII. El carácter "implicativo" de este compromiso con la verdad y las tres formas en que suele presentarse; $y$, VIII. La importancia de un análisis detallado de estas formas para la doctrina de los infortunios y para el establecimiento de un paralelo más apropiado entre los realizativos y los constatativos. 


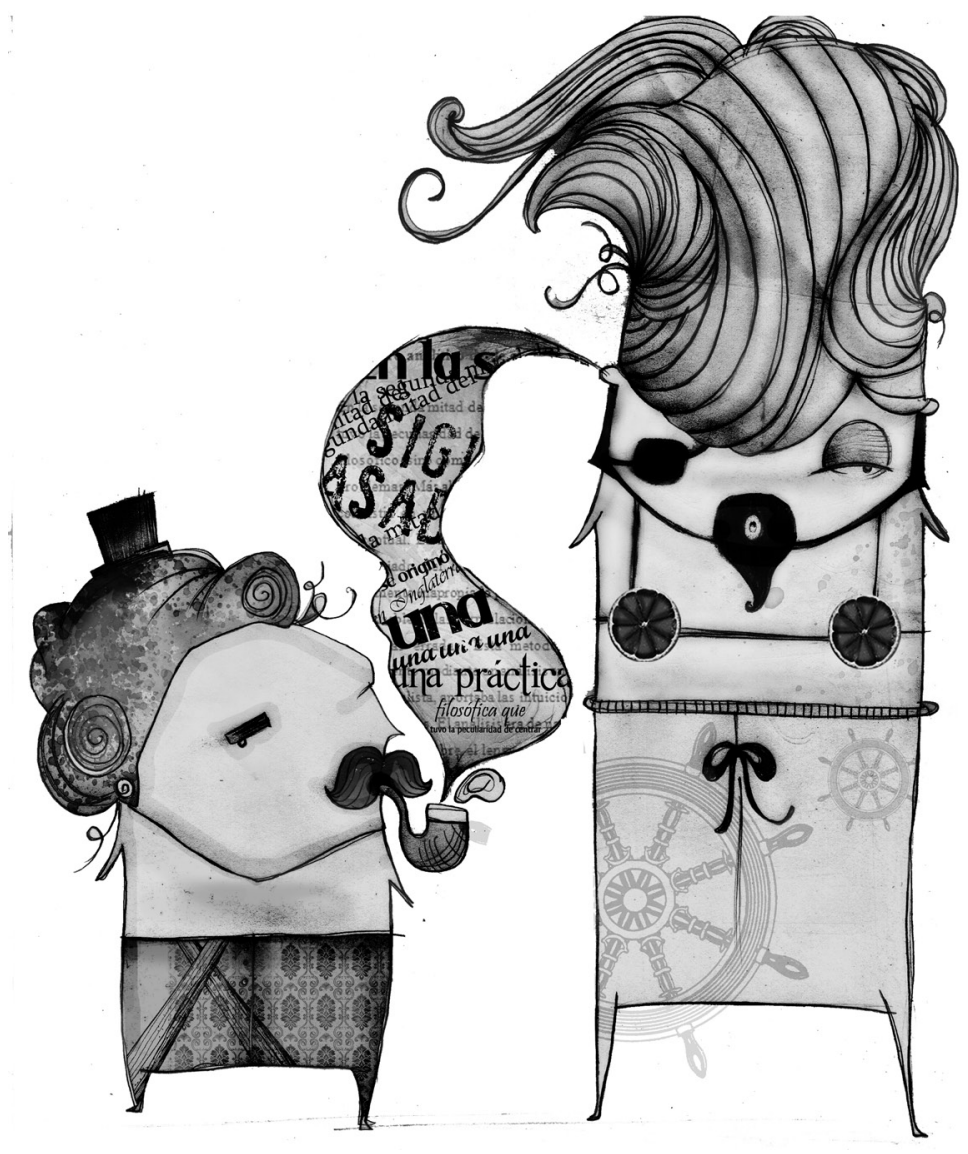

Notas

1 Una traducción más literal sería la de emisiones "performativas" pero tal neologismo puede ser impropio si se considera que el verbo inglés to perform (ejecutar, llevar a cabo), del cual deriva Austin el neologismo performative (perform + -ative) se traduce adecuadamente al español como "realizar" del cual se deriva "realizativas". Sin embargo, hay quienes en su lugar traducen "actuativas" u “operativas". (Cfr. Austin, 1988: 47-48; nota 8). El término “constatativas" es menos problemático puesto que se deriva de constatar (verificar, confrontar) y es fiel traducción del inglés constative, que a su vez proviene de constat(er) + -ive.

2 Advierto que puede resultar problemático interpretar $\mathrm{P}_{12}$ como una expresión constatativa, ya que la inclusión del verbo 'deber' hace de éste un enunciado normativo (deontológico) que muchos no incluirían en el tipo de los constatativos por pertenecer al campo de la ética y la moral. Creo, no obstante, que este problema se soluciona si consideramos una expresión normativa D de la forma "debo hacer X", al que $\mathrm{P}_{12}$ se referiría mediante una formulación como: "actué de acuerdo con D", u otra similar.

\section{Referencias}

Alston, William P. (1997). A realist Conception of Truth. New York, USA: Cornell University Press.

Austin, John Langshaw. (1998). Cómo Hacer Cosas con Palabras. Palabras y acciones. Trad. Genaro R. Carrió y Eduardo A. Rabossi. Barcelona, España: Paidós. (1975). Emisiones Realizativas. En J. O. Urson y G. J. Warnock (Comps.),

Ensayos Filosóficos (pp. 217-231) Trad. Alfonso García Suárez. Madrid, España: Ediciones de la Revista de Occidente. Ayer, Alfred (Comp.). (1978). El positivismo lógico. Madrid, España: FCE.

Bach, Kent. (1975). Performatives are statements too. Philosophical Studies, (28), 229-236.

Bach, Kent y Harnish, R. M. (1992). How performatives really work: a reply to Searle. Linguistics and Philosophy, (15), 93-110.

Bal. M. (2006). Narrativity and voice. En Jacob L. Mey (Ed.), Concise Encyclopedia of Pragmatics (2a Ed.) (pp. 661-665)

Oxford, UK: Elsevier.

Benveniste, E. (1966). Problèmes de linguistique générale (I). París, Francia: Gallimard.

Borradori, Giovanna. (1996). Conversaciones filosóficas. El nuevo pensamiento norteamericano. Santafé de Bogotá, Colombia: Norma. 


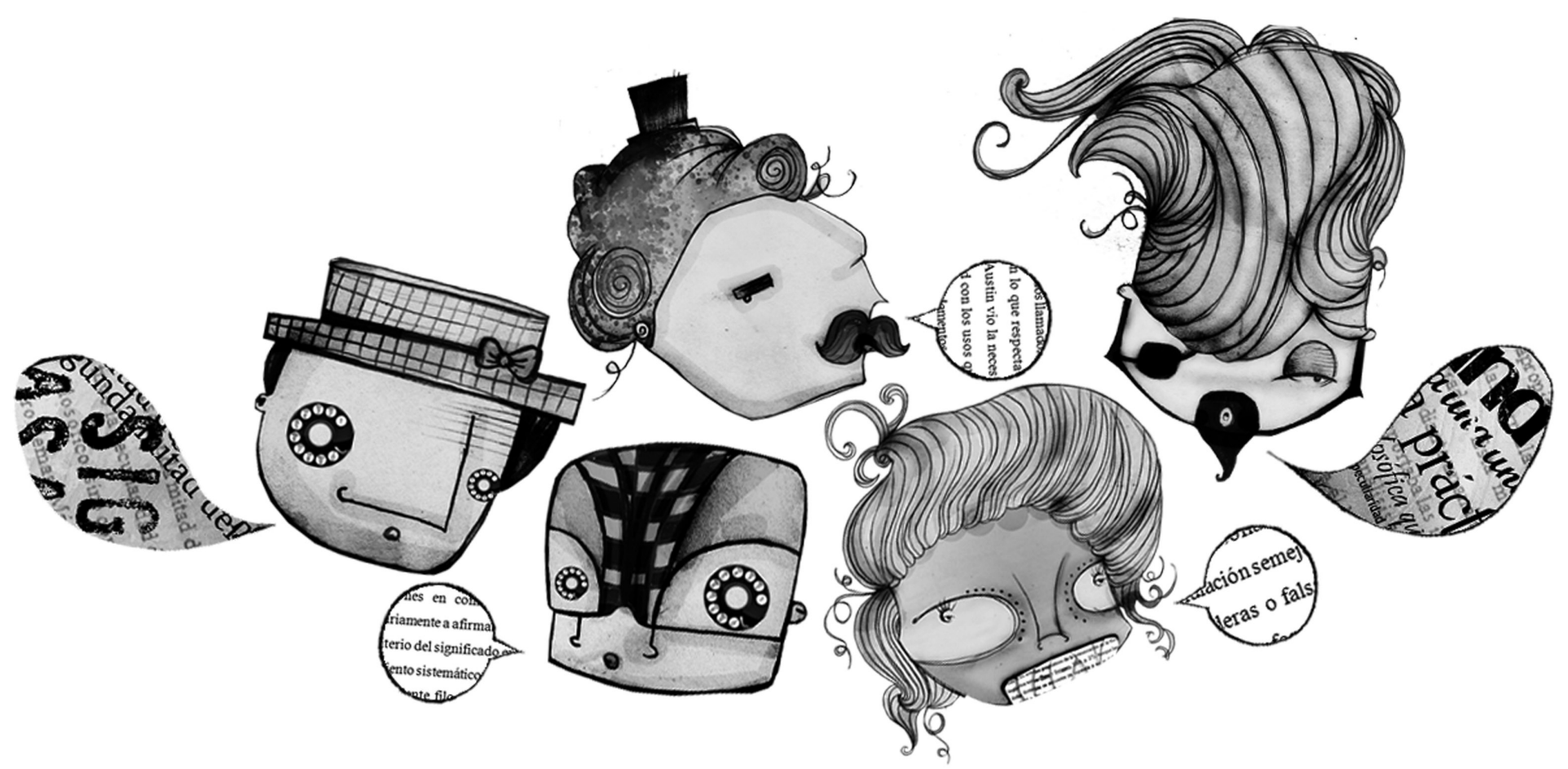

Cardona, Giorgio R. (1991). Diccionario de Lingüística. Barcelona, España: Ariel.

Carnap, Rudolf. (1978). La antigua y la nueva lógica. En Alfred Ayer (Comp.), El positivismo lógico (pp. 139-167).

Madrid, España: FCE.

Casamiglia, H. y Tusón, A. (1999). Las cosas del decir. Manual de análisis del discurso. Barcelona, España: Ariel.

Cavell, Stanley. (1996). Apología del escepticismo. En Giovanna Borradori (Dir.). Conversaciones filosóficas.

El nuevo pensamiento norteamericano (pp. 175-198) Santafé de Bogotá, Colombia: Norma.

Danet, B. (1980). Language in the legal process. Law and Society Review, (14), 445-464.

Degan, L. (2006). Speech Acts and Grammar. En Jacob L. Mey (Ed.), Concise Encyclopedia of Pragmatics (2a Ed.) (pp. 1009-1015) Oxford, UK: Elsevier.

Dummett, Michael A. E. (1994). The logical Basis of Metaphysis. Cambridge, USA:The Harvard University Press.

Frazer, James George. (1993). La Rama Dorada. Magia y Religión. Trad. Elizabethy Tadeo I. Campuzano. Santafé de Bogotá, Colombia: Fondo de Cultura Económica.

Gómez, Adolfo León. (1988). Filosofía analítica y lenguaje Cotidiano. Introducción a la filosofía del lenguaje de J. L. Austin y sus desarrollos posteriores. Santafé de Bogotá, Colombia: Biblioteca Colombiana de Filosofía.

Hempel, Carl. (1978). Problemas y cambios en el criterio empirista del significado. En Alfred Ayer (Comp.),

El positivismo lógico (pp. 115-136) Madrid, España: FCE.

Hencher, M. (1980). Speech acts and the law. En R. Shuy y A. Shnukal (Eds.), Language use and the uses of language (pp. 245-256). Georgetown,USA: Georgetown University Press.

Huang, Y. (2006). Speech Acts. En Jacob L. Mey (Ed.), Concise Encyclopedia of Pragmatics (2a Ed.) (pp. 1000-1009) Oxford, UK: Elsevier.

Jori, M. (1994). Legal performatives. En R. E. Asher (Ed.), The encyclopedia of language and linguistics (pp. 2092-2097). Oxford, UK: Pergamon Press.

Levinson, S. C. (1983). Pragmatics. Cambridge, USA: Cambridge University Press.

Maley, Y. (1994). The language of the law. En Gibbons (Ed.), Language and the law (pp. 11-50) London, UK: Longman.

Mey, Jacob. (2006) Literary Pragmatics. En Jacob L. Mey (Ed.), Concise Encyclopedia of Pragmatics (2a Ed.) (pp. 549-545)

Oxford, UK: Elsevier.

Norris, Christopher. (2004). Language, Logic and Epistemology: A Modal-Realist Approach. New York, USA: Palgrave Macmillan.

Pater, W. A. de y Swiggers, P. (2009). Austin, John L. En Jacob L. Mey (Ed.), Concise Encyclopedia of Pragmatics (2a Ed.) (pp. 27-28) Oxford, UK: Elsevier.

Proudfoot, Michael y Lacey, A. R. (2010). The Routledge Dictionary of Philosophy (4a Ed.) New York, USA: Routledge.

Quine, W. O. (1996). La lógica del siglo XX. En Giovanna Borradori (Dir.), Conversaciones filosóficas. El nuevo pensamiento norteamericano (pp. 49-65) Santafé de Bogotá, Colombia: Norma. 


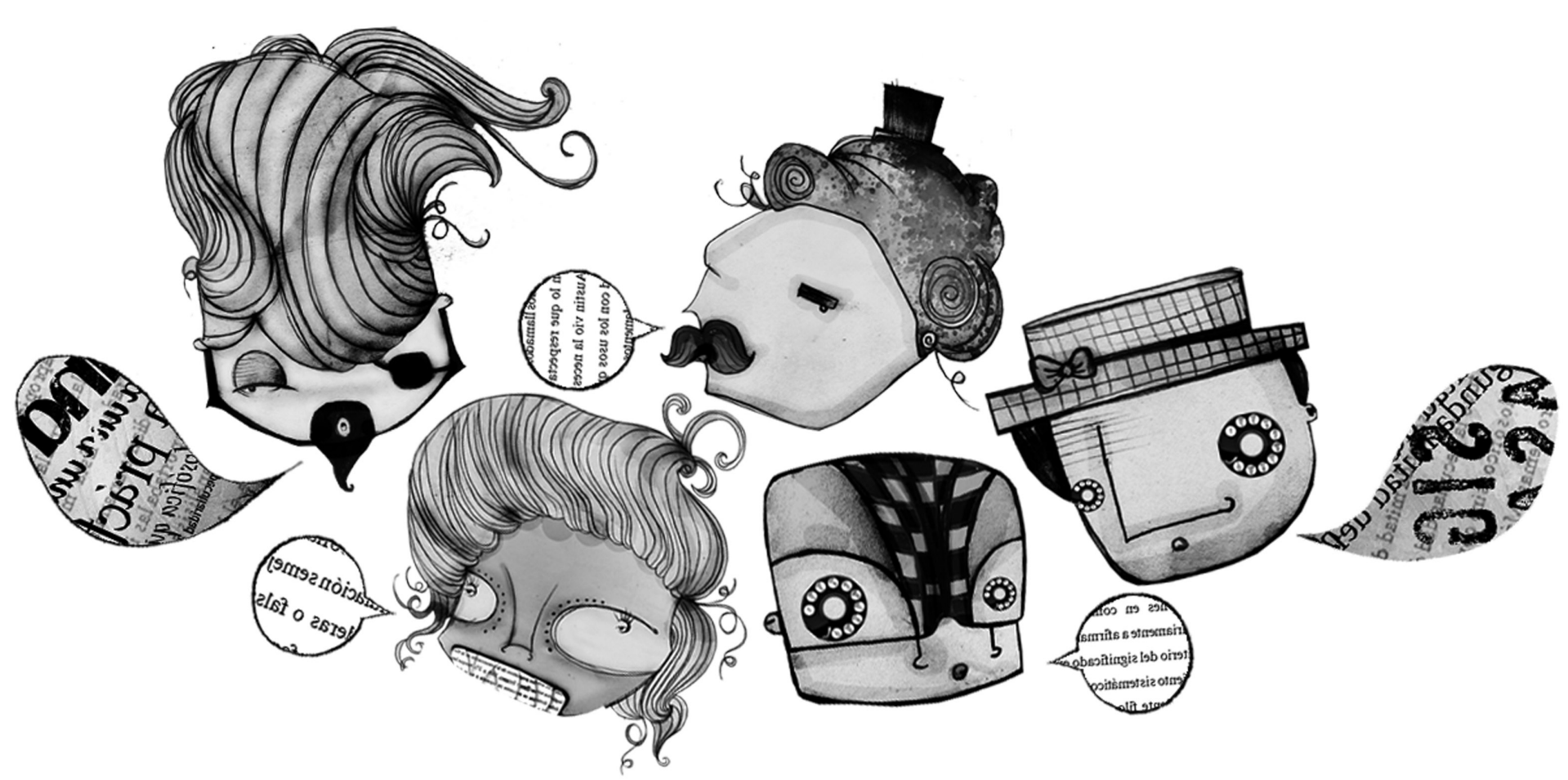

Recanati, F. (2006). Pragmatics and Semantics. En Laurence R. Horn y Gregory Warden (Eds.), The Handbook of Pragmatics

(pp. 442-462) Oxford: UK: Blackwell Publishing.

Reimer, Marga. (1995). Performative utterances a reply to Bach and Harnish. Linguistics and Philosophy, (18), 655-575.

Reyes, Graciela. (1995). El Abecé de la pragmática. Madrid: España, Arcos libro.

(2002). Metapragmática. Lenguaje sobre lenguaje, ficciones y figuras. Madrid, España: Secretariado de publicaciones e intercambio editorial

Russell, Bertrand. (1978). El atomismo lógico. En Alfred Ayer (Comp.), El positivismo lógico (pp. 37-56). Madrid, España: FCE.

Sadock, Jerrold. (2006). Speech Acts. En Laurence R. Horn y Gregory Warden (Eds.), The Handbook of Pragmatics (pp. 53-73)

Oxford, UK: Blackwell Publishing.

Searle, John R. (1975). A taxonomy of illocutionary acts. En Gunderson K (ed.), Language, mind and knowledge. (pp. 344-379) Minneapolis, USA: University of Minnesota Press.

(1979). Expression and meaning. Studies in the theory of speech acts. Cambridge, USA:

Cambridge University Press.

(1986). Actos de Habla. Ensayo de filosofía del lenguaje. Madrid, España: Editorial Cátedra.

. (1993). La filosofía del lenguaje. En Bryan Magee (Dir.), Los hombres detrás de las ideas. Algunos creadores de la filosofía contemporánea (pp. 190-211) México D.F., México: FCE.

Sorensen, Jesper. (2000). Essence, Schema, and Ritual Action:Towards a Cognitive Theory of Magic. PhD thesis, Faculty of Theology,

University of Aarhus.

Stanley, Jason. (2007). Language in Context. Selected Essays. Oxford, UK: Clarendon Press.

Stygall, G. (1994). Trial language: differential discourse processing and discursive formation. Amsterdam, Holland: Benjamins.

Sweetser, Eve. (2001). Blended spaces and performativity. Cognitive Linguistics, (11), 305-34.

Thomas, J. (1995). Meaning in interaction. An introduction to pragmatics. London, UK: Longman.

Truckenbrodt, H. (2004). Introduction to general linguistics. Semantics 7: pragmatics: speech acts.

URL: http://www2.sfs.nphil.uni-tuebingen.de/_hubert/intro_ling/Script/sc_2004_01_08.pdf.

Williams, Bernard. (1993). El hechizo de la filosofía Lingüística. En Bryan Magee (Dir.), Los hombres detrás de las ideas. Algunos creadores de la filosofía contemporánea (pp. 142-157) México D.F., México: FCE.

Wittgenstein, Ludwig. (1921). Tractatus Logico-Philosophicus. Londres, UK: Routledge and Kegan Paul.

. (1976). Bemerkungen über Frazers The Golden Bough. Dordrecht, Holland: D. Reidel Publishing Company. . (1999). Investigaciones Filosóficas. Barcelona, España: Editorial Altaya. 